\title{
Three-dimensional earthquake analysis of roller-compacted concrete dams
}

\author{
M. E. Kartal \\ Bulent Ecevit University, Department of Civil Engineering, Zonguldak, Turkey \\ Correspondence to: M. E. Kartal (murat_emre_kartal@hotmail.com) \\ Received: 20 March 2012 - Revised: 20 May 2012 - Accepted: 22 May 2012 - Published: 24 July 2012
}

\begin{abstract}
Ground motion effect on a roller-compacted concrete (RCC) dams in the earthquake zone should be taken into account for the most critical conditions. This study presents three-dimensional earthquake response of a RCC dam considering geometrical non-linearity. Besides, material and connection non-linearity are also taken into consideration in the time-history analyses. Bilinear and multilinear kinematic hardening material models are utilized in the materially non-linear analyses for concrete and foundation rock respectively. The contraction joints inside the dam blocks and dam-foundation-reservoir interaction are modeled by the contact elements. The hydrostatic and hydrodynamic pressures of the reservoir water are modeled with the fluid finite elements based on the Lagrangian approach. The gravity and hydrostatic pressure effects are employed as initial condition before the strong ground motion. In the earthquake analyses, viscous dampers are defined in the finite element model to represent infinite boundary conditions. According to numerical solutions, horizontal displacements increase under hydrodynamic pressure. Besides, those also increase in the materially non-linear analyses of the dam. In addition, while the principle stress components by the hydrodynamic pressure effect the reservoir water, those decrease in the materially non-linear time-history analyses.
\end{abstract}

\section{Introduction}

Roller-compacted concrete (RCC) dams are designed as conventional concrete structures. But the construction methods, concrete mix design, and details of the appurtenant structures are different in these structures. The construction techniques utilized in RCC dams are analogous to those used for embankment dams. These techniques provide rapid placement and economic advantages for construction. RCC dams are relatively dry, lean, zero-slump concrete material containing coarse and fine aggregate that is consolidated by external vibration using vibratory rollers, bulldozers, and other heavy equipment. Construction procedures associated with RCC require particular attention be given in the layout and design to watertightness and seepage control, horizontal and transverse joints, facing elements, and appurtenant structures. In the hardened condition, mechanical properties of RCC dams take after those of conventional concrete dams (USACE, 1995).

The investigators usually focused on the thermal analysis of RCC dams, because thermal cracking may create a leakage path to the downstream face that is aesthetically undesirable. Zhang et al. (1996) carried out thermal stress analysis for the investigation of cracks in a RCC arch dam. Their analyses showed that the stress distribution in the arch could be improved by artificial short joints located upstream of the abutment, and the water pressure should be kept constant during February-April for the consideration of stability of cracks. Chen et al. (2001) developed a 3-D finite element relocating mesh method for simulation analysis of temperature and thermal stress distribution in a roller-compacted concrete dam during the construction period. Noorzaei et al. (2006) performed thermal and structural analysis of Kinta RCC gravity dam, which is the first RCC dam in Malaysia, using the developed two-dimensional finite element code. Then, the authors compared predicted temperatures obtained from the finite element code with actual temperatures measured in the field using thermocouples installed within the dam body, and they found them to be in good agreement. Jaafar et al. (2007) developed a finite element-based computer code to determine the temperatures within the dam body. According to performed thermal analysis of a RCC dam, changing the placing schedule can optimize the locations 
of maximum temperature zones. Abdulrazeg et al. (2010) performed three- dimensional coupled thermal and structural analysis of roller-compacted concrete dams. They assessed crack development within the dam body using the proposed crack index. This method remarkably reduces the total number of elements and nodes when the dam height was increased. Zhang et al. (2011) simulated and analyzed the temperature field and thermal stress of certain RCC gravity dams in cold regions using the material properties of rollercompacted concrete by three-dimensional finite element relocating mesh method. As a result, the authors indicated that superficial insulation prevented surface cracks from forming.

In Turkey, $92 \%$ of the dams are in the earthquake zones. Therefore, earthquake response of the dams should be performed. However, earthquake response of RCC dams has rarely aroused interest of researchers. Seismic analysis of RCC dams also attracted researchers. Liapichev (2003) carried out finite element seismic analyses of RCC gravity dams considering two strong earthquakes (MDE and MCE) with ground horizontal and vertical accelerograms with peak values of $0.2 \mathrm{~g}$ and $0.4 \mathrm{~g}$. In contrast to MDE case, the author obtained elasto-plastic dam behavior and partial opening of RCC joints in the lower half of the dam in the MCE case. Bayraktar et al. (2009) investigated near- and far-fault ground motion effects on seismic performance evolution of a RCC dam considering hydrodynamic pressure by using 2-D finite element model, considering that earthquake analysis nearfault ground motion effects were more affective than far-fault ground motion. Huang (2010) analyzed seismic safety of left bank dam monoliths of Jin'anqiao hydropower station using living elements and death elements by finite element methods considering cutting transverse joints. The author indicated that Jin'anqiao hydropower station RCC gravity dam had reasonable design and could resist a precautionary earthquake.

This study aims to fill the lack of the studies related to the seismic response of RCC dams. Therefore, 3-D earthquake response is investigated using the finite element method. Çine RCC dam is considered in the numerical analyses. In this study, geometrically and materially non-linear analyses are also performed together with linear analyses. Bilinear kinematic hardening material model is considered for dam concrete, and multilinear kinematic hardening material model is considered for dam foundation in the materially non-linear analyses. Empty and full reservoir conditions are considered. Hydrodynamic pressure of the reservoir water is modeled by using three- dimensional fluid finite elements based on the Lagrangian method. Dam-foundation-reservoir interaction is considered in the finite element model. In addition to this, the transverse contraction joints are also considered in this model. This is realized by contact elements. In the numerical analysis, firstly, fixed boundary condition is considered at foundation soil boundaries, and roller-supported boundary conditions are considered at reservoir boundaries. Then, static analysis is performed due to gravity effect in empty reservoir case and, in addition to this, hydrostatic pressure is also considered in full reservoir case. After the initial condition, which is gravity load and hydrostatic pressure, fixed and roller- supported boundary conditions are released. Subsequently, viscous dampers are defined in the finite element model boundaries to represent infinite boundary condition. In the earthquake analyses, east-west, north-south and vertical components of the 1999 Düzce earthquake record are utilized. Thus, earthquake loading is applied on the settled situation of the RCC dam. According to linear and non-linear seismic analyses, hydrodynamic pressure increases the horizontal displacements and principle stress components. Besides, while the horizontal displacements increase with materially non-linear analyses, principle stress components decrease as compared to linear analysis.

\section{Formulation of dam-foundation-reservoir interac- tion by the Lagrangian approach}

The formulation of the fluid system based on the Lagrangian approach is presented as following (Wilson and Khalvati, 1983; Calayır, 1994). In this approach, fluid is assumed to be linearly compressible, inviscid and irrotational. For a general three-dimensional fluid, pressure-volumetric strain relationships can be written in matrix form as follows:

$$
\left\{\begin{array}{c}
P \\
P_{\mathrm{x}} \\
P_{\mathrm{y}} \\
P_{\mathrm{z}}
\end{array}\right\}=\left[\begin{array}{cccc}
C_{11} & 0 & 0 & 0 \\
0 & C_{22} & 0 & 0 \\
0 & 0 & C_{33} & 0 \\
0 & 0 & 0 & C_{44}
\end{array}\right]\left\{\begin{array}{c}
\varepsilon_{\mathrm{v}} \\
w_{\mathrm{x}} \\
w_{\mathrm{y}} \\
w_{\mathrm{z}}
\end{array}\right\}
$$

where $P, C_{11}$, and $\varepsilon_{\mathrm{v}}$ are the pressures that are equal to mean stresses, the bulk modulus and the volumetric strains of the fluid, respectively. Since irrotationality of the fluid is considered like penalty methods (Zienkiewicz and Taylor, 1989; Bathe, 1996), rotations and constraint parameters are included in the pressure-volumetric strain equation (Eq. 1) of the fluid. In this equation, $P_{\mathrm{x}} P_{\mathrm{y}}$, and $P_{\mathrm{z}}$, are the rotational stresses; $C_{22}, C_{33}$ and $C_{44}$ are the constraint parameters, and $w_{\mathrm{x}}, w_{\mathrm{y}}$ and $w_{\mathrm{z}}$ are the rotations about the cartesian axis $\mathrm{x}, \mathrm{y}$ and $\mathrm{z}$.

In this study, the equations of motion of the fluid system are obtained using energy principles. Using the finite element approximation, the total strain energy of the fluid system may be written as

$\pi_{e}=\frac{1}{2} \boldsymbol{U}_{\mathrm{f}}^{\mathrm{T}} \mathbf{K}_{\mathrm{f}} \boldsymbol{U}_{\mathrm{f}}$

where $\boldsymbol{U}_{\mathrm{f}}$ and $\mathbf{K}_{\mathrm{f}}$ are the nodal displacement vector and the stiffness matrix of the fluid system, respectively. $\mathbf{K}_{\mathrm{f}}$ is obtained by the sum of the stiffness matrices of the fluid elements as follows: 


$$
\begin{aligned}
& \mathbf{K}_{\mathrm{f}}=\sum \mathbf{K}_{\mathrm{f}}^{\mathrm{e}} \\
& \mathbf{K}_{\mathrm{f}}^{\mathrm{e}}=\int_{\mathrm{V}} \mathbf{B}_{\mathrm{f}}^{\mathrm{e}^{\mathrm{T}}} \mathbf{C}_{\mathrm{f}} \mathbf{B}_{\mathrm{f}}^{\mathrm{e}} \mathrm{d} \mathrm{V}^{\mathrm{e}}
\end{aligned}
$$

where $\mathbf{C}_{\mathrm{f}}$ is the elasticity matrix consisting of diagonal terms in Eq. (1). $\mathbf{B}_{\mathrm{f}}^{\mathrm{e}}$ is the strain-displacement matrix of the fluid element.

An important behavior of fluid systems is the ability to displace without a change in volume. For reservoir and storage tanks, this movement is known as sloshing waves, in which the displacement is in the vertical direction. The increase in the potential energy of the system because of the free surface motion can be written as

$\pi_{s}=\frac{1}{2} \boldsymbol{U}_{\mathrm{sf}}^{\mathrm{T}} \mathbf{S}_{\mathrm{f}} \boldsymbol{U}_{\mathrm{sf}}$

where $\boldsymbol{U}_{\text {sf }}$ and $\mathbf{S}_{\mathrm{f}}$ are the vertical nodal displacement vector and the stiffness matrix of the free surface of the fluid system, respectively. $\mathbf{S}_{\mathrm{f}}$ is obtained by the sum of the stiffness matrices of the free surface fluid elements as follows:

$$
\left.\begin{array}{c}
\mathbf{S}_{\mathrm{f}}=\sum_{\mathrm{f}} S_{\mathrm{f}}^{\mathrm{e}} \\
\mathbf{S}_{\mathrm{f}}^{\mathrm{e}} g \int_{\mathrm{A}} \boldsymbol{h}_{\mathrm{s}}^{\mathrm{T}} \boldsymbol{h}_{\mathrm{s}} \mathrm{d} A^{\mathrm{e}}
\end{array}\right\}
$$

where $\boldsymbol{h}_{\mathrm{S}}$ is the vector consisting of interpolation functions of the free surface fluid element. $\rho_{\mathrm{f}}$ and $g$ are the mass density of the fluid and the acceleration due to gravity, respectively. Besides, kinetic energy of the system can be written as

$\mathrm{T}=\frac{1}{2} \dot{\boldsymbol{U}}_{\mathrm{f}}^{\mathrm{T}} \mathbf{M}_{\mathrm{f}} \dot{\boldsymbol{U}}_{\mathrm{f}}$

where $\dot{\boldsymbol{U}}_{\mathrm{f}}$ and $\mathbf{M}_{\mathrm{f}}$ are the nodal velocity vector and the mass matrix of the fluid system, respectively. $\mathbf{M}_{\mathrm{f}}$ is also obtained by the sum of the mass matrices of the fluid elements as follows:

$$
\left.\begin{array}{c}
M_{\mathrm{f}}=\sum_{\mathrm{f}} M_{\mathrm{f}}^{\mathrm{e}} \\
M_{\mathrm{f}}^{\mathrm{e}}=\rho_{\mathrm{f}} \int_{\mathrm{V}} H^{\mathrm{T}} \mathbf{H} \mathrm{d} V^{\mathrm{e}}
\end{array}\right\}
$$

where $\mathbf{H}$ is the matrix consisting of interpolation functions of the fluid element. If Eqs. (2), (4) and (6) are combined using the Lagrange's equation (Clough and Penzien, 1993), the following set of equations is obtained:

$$
\mathbf{M}_{\mathrm{f}} \ddot{\mathbf{U}}_{\mathrm{f}}+\mathbf{K}_{\mathrm{f}}^{*} \mathbf{U}_{\mathrm{f}}=\mathbf{R}_{\mathrm{f}}
$$

where $\mathbf{K}_{\mathrm{f}}^{*}, \ddot{\mathbf{U}}_{\mathrm{f}}, \mathbf{U}_{\mathrm{f}}$ and $\mathbf{R}_{\mathrm{f}}$ are the system stiffness matrix, including the free surface stiffness, the nodal acceleration and displacement vectors and time-varying nodal force vector for the fluid system, respectively. In the formation of the fluid element matrices, reduced integration orders are used (Wilson and Khalvati, 1983).

The equations of motion of the fluid system (Eq. 8) have a similar form as those of the structure system. To obtain the

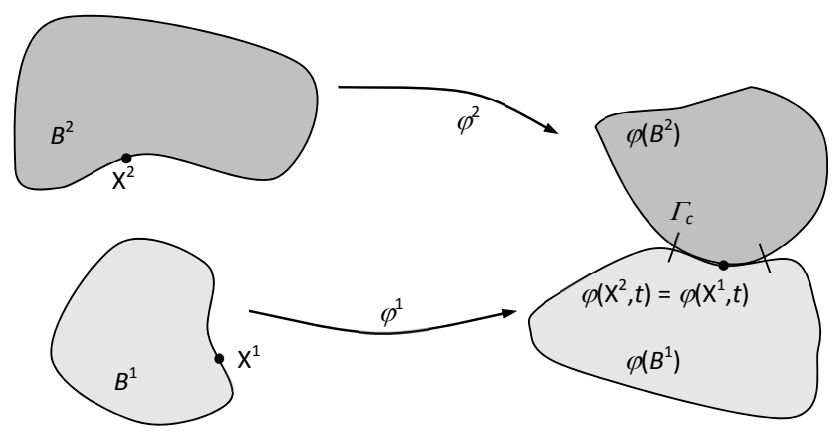

Fig. 1. Finite deformation contact (Wriggers, 2006).

coupled equations of the fluid-structure system, the determination of the interface condition is required. Since the fluid is assumed to be inviscid, only the displacement in the normal direction to the interface is continuous at the interface of the system. Assuming that the structure has the positive face and the fluid has the negative face, the boundary condition at the fluid-structure interface is

$U_{n}^{-}=U_{n}^{+}$

where $U_{n}$ is the normal component of the interface displacement (Akkas et al., 1979). Using the interface condition, the equation of motion of the coupled system to ground motion including damping effects is given by

$\mathbf{M}_{\mathrm{c}} \ddot{\boldsymbol{U}}_{\mathrm{c}}+\mathbf{C}_{\mathrm{c}} \dot{\boldsymbol{U}}_{\mathrm{c}}+\mathbf{K}_{\mathrm{c}} \boldsymbol{U}_{\mathrm{c}}=\boldsymbol{R}_{\mathrm{c}}$

in which $\mathbf{M}_{\mathrm{c}}, \mathbf{C}_{\mathrm{c}}$, and $\mathbf{K}_{\mathrm{c}}$ are the mass, damping and stiffness matrices for the coupled system, respectively. $\boldsymbol{U}_{\mathrm{c}}, \dot{\boldsymbol{U}}_{\mathrm{c}}$, $\ddot{\boldsymbol{U}}_{\mathrm{c}}$ and $\boldsymbol{R}_{\mathrm{c}}$ are the vectors of the displacements, velocities, accelerations and external loads of the coupled system, respectively.

\section{Contact mechanics}

Structural response is mostly depended on contact between discrete systems. Contact problems may include small and large deformations. Consider $X^{1}$ and $X^{2}$ nodes on $B^{a}$ bodies in Fig. 1, which have different initial conditions. After deformations, $\phi\left(X^{2}\right)=\phi\left(X^{1}\right)$, these nodes come into the same position in the $\Gamma_{\mathrm{c}}$ boundaries (Fig. 1). Consider $B^{a}$ elastic bodies, $a=1,2, \Gamma^{a}$ boundary of the $B^{a}$ body consists of $\Gamma_{\sigma}^{a}$ with prescribed surface loads, $\Gamma_{u}^{a}$ with prescribed displacements and $\Gamma_{\mathrm{c}}^{a}$, in which $B^{1}$ and $B^{2}$ bodies come into contact (Wriggers, 2006).

\subsection{Constraint formulation}

The mathematical condition for non-penetration is stated as $g N \geq 0$, which precludes the penetration of body $B^{1}$ into body $B^{2}$. Here, $g N$ is named as normal gap. When $g N$ is 


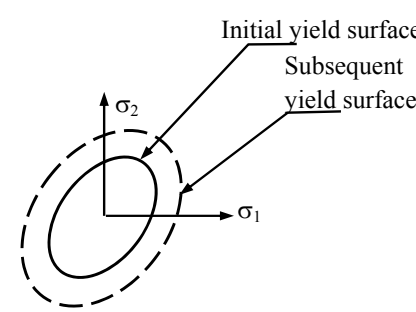

a) Isotropic Hardening

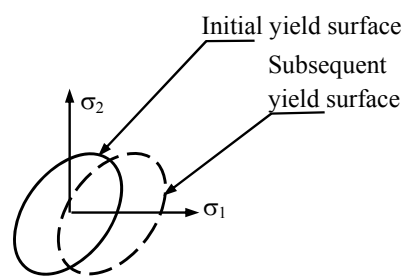

b) Kinematic Hardening

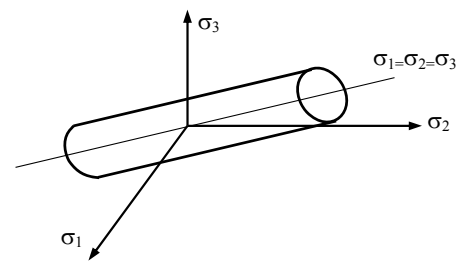

a) Three Dimensional Case

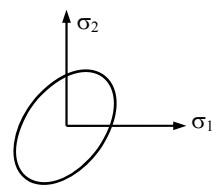

b) Two Dimensional Case

Fig. 3. Yield surfaces for kinematic hardening model.

method is to combine either the penalty method or the constitutive interface laws with Lagrange multiplier methods. This method was applied to contact problems for frictionless contact (Wriggers et al., 1985; Kikuchi and Oden, 1988), and then this approach was extended to large displacement contact problems including friction (Alart and Curnier, 1991; Laursen and Simo, 1993).

must be non-zero in the contact interface. In the upper equation, $t_{T}^{1}{ }^{\beta}$, tangential stress is zero in the case of frictionless contact. If the bodies come into contact, $g N=0$ and $p N<0$ where $p N$ is normal contact pressure. If there is a gap between the bodies, $g N>0$ and $p N=0$. This leads to some statements that are known as Hertz-Signorini-Moreau conditions (Wriggers, 2006):

$g N \geq 0 ; \quad p N \leq 0 ; \quad p N g N=0$

In Eq. (11) Cauchy theorem is given by Cauchy stress. Correspondingly, the stress vector can be written two different ways for nominal stresses or P-first Piola-Kirchhoff stress:

$t=\sigma n$ or $T=P N$

\subsection{Treatment of contact constraints}

There are various methods that can be applied to incorporate the contact constraints into the variational formulation. When the contact interface is known, the weak form can be written as equality:

$\sum_{\gamma=1}^{2}\left\{\int_{B^{\gamma}} \tau^{\gamma} \cdot \operatorname{grad} \eta^{\gamma} d V-\int_{B^{\gamma}} \bar{f}^{\gamma} \cdot \eta^{\gamma} d V-\int_{\Gamma_{\sigma}^{\gamma}} \bar{t}^{\gamma} \cdot \eta^{\gamma} d A\right\}+C_{\mathrm{c}}=0$

Here, $C_{\mathrm{c}}$ is the contact contributions related to the active constraint set. $\eta^{\gamma} \in V$ is named as test function or virtual displacement and which is zero at the boundary $\Gamma_{\phi}^{\gamma}$, where the deformations are prescribed. $\tau^{\gamma}, \bar{f}^{\gamma}$ and $\bar{t}^{\gamma}$ are the Kirchhoff stress, the body force of body $B^{\gamma}$ and the surface traction applied on the boundary of $B^{\gamma}$, respectively.

There are several different variants for the formulation of $C_{\mathrm{c}}$. One of the methods, which regularize the nondifferentiable normal contact and friction terms is augmented Lagrangian method used in this study. The main idea of this

\section{Non-linear material models}

There are two basic hardening rules: isotropic and kinematic rules (Fig. 2). These rules require uniaxial stressstrain relationships that are easier for practical applications. The uniaxial stress-strain relationship includes three regions: (i) stress-strain relationship prior to yield; (ii) yield criteria; and (iii) stress-strain relationships for the post-yield range. The yield surfaces in two- and three-dimensional cases are shown in Fig. 3 for kinematic hardening model.

The isotropic hardening model deals satisfactorily with respect to monotonic loadings, stress level confined to a limited sub-domain of the loading surface and material with negligible hardening. However, these assumptions do not apply strictly to many real situations, especially the last one. The kinematic hardening is often and more successfully employed, thanks to its capability of representing cyclic loads with acceptable approximation. Even though it can accommodate to some extent the Bauschinger effect, still it underestimates the real cyclic response, as opposed to the isotropic case.

\subsection{Bilinear kinematic hardening model}

The bilinear kinematic model is the simplest and most widely used mode, as shown in Fig. 4. This model uses von Mises yield criterion with the associated flow rule. The elastic range remains constant throughout the various loading stages, while the kinematic hardening rule for the yield surface is assumed to be a linear function of the increment of plastic strain. The tangent modulus, required for updating the element stiffness matrix, is the Young's modulus $E$ for stresses lower than the yield stress $f_{\mathrm{y}}$ and $\mu E$ for stresses of value higher than. 


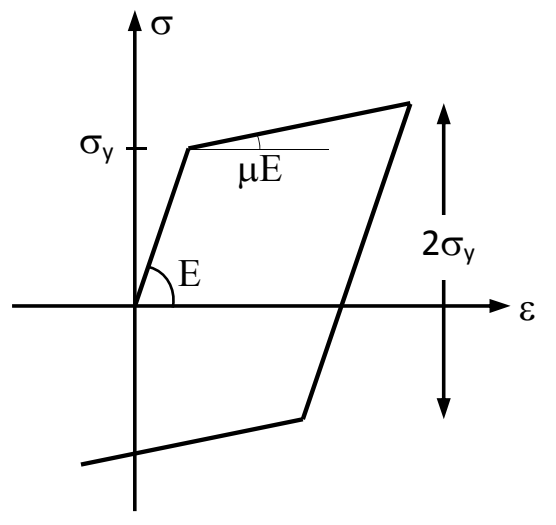

Fig. 4. Stress-Strain behavior of bilinear kinematic hardening model for Bauschinger effect.

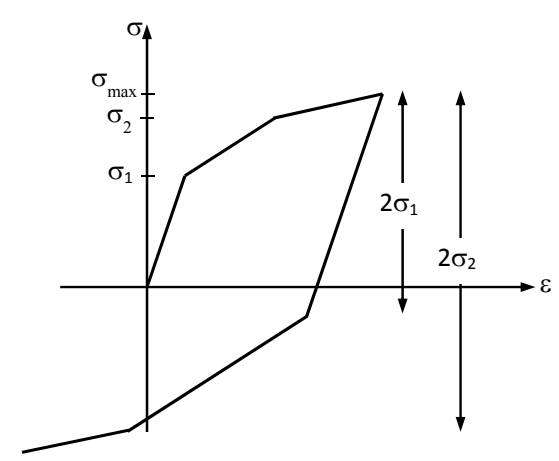

Fig. 5. Stress-strain behavior of multilinear kinematic hardening model for Bauschinger effect.

\subsection{Multilinear kinematic hardening model}

The multilinear kinematic hardening model can be used to model plasticity behavior under cycling loading. This model uses the Besseling model to characterize the perfectly plastic material behavior. The material behavior is assumed to be composed of various sections, all subjected to the same total strain, but each subsection having a different yield strength. Each subvolume has a simple stress-strain response but when combined the model can represent complex behavior. This allows a multilinear stress-strain curve that exhibits the Bauschinger (kinematic hardening) effect (Fig. 5). The total response is obtained by weighted average behavior of all the sections. Individual weights are derived from the uniaxial stress-strain curve (Fig. 6). The uniaxial behavior is described by a piece-wise linear "total stress-total strain curve", starting at the origin, with positive stress and strain values. The slope of the first section of the curve must correspond to the elastic modulus of the material and no section slope should be larger. The slope of the stress-strain curve is assumed to be zero beyond the last user-defined stress-strain data point.

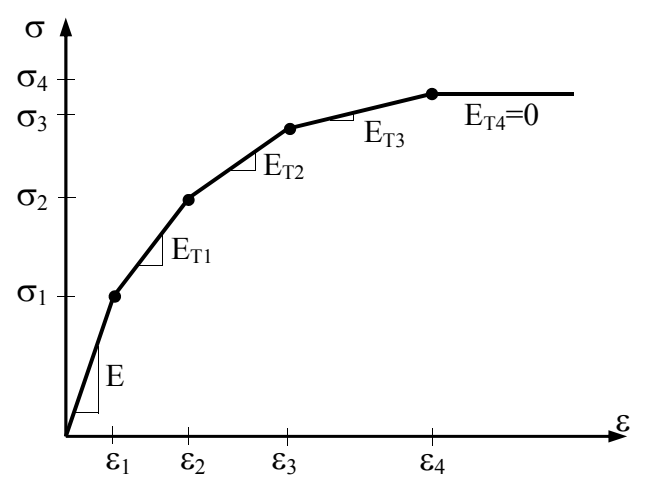

Fig. 6. Uniaxial compressive stress-strain behavior for multilinear kinematic hardening model.

\section{Numerical model of Çine RCC dam}

\subsection{The model of Çine RCC dam}

Çine dam, located approximately $16 \mathrm{~km}$ southeast of Çine, Aydın, was constructed in 2010 by General Directorate of State Hydraulic Works (Fig. 7) (DSI, 2012). It was established on Çine River. This dam was projected as a rollercompacted concrete dam. The reservoir is used for irrigation and energy purposes. The dam crest is $372.5 \mathrm{~m}$ in length and $9 \mathrm{~m}$ wide. The maximum height and base width of the dam are $136.5 \mathrm{~m}$ and $142.5 \mathrm{~m}$, respectively. The maximum height of the reservoir water is considered as $98.77 \mathrm{~m}$. The two- dimensional cross sections of the dam are shown in Fig. 8f. The annual total power generation capacity is $118 \mathrm{GW}$.

\subsection{Material properties of Çine RCC dam}

The three-dimensional finite element model of Çine dam is modeled considering two-layered foundation rock. One of the layers begins from crest level to base of the dam body. The other begins from the base of the dam body to bottom of the foundation. The material properties of Çine roller- compacted concrete dam body and foundation are given in Table 1 . The tensile strength and the compressive strength of the concrete used in the dam body are $1.3 \mathrm{MPa}$ and $20 \mathrm{MPa}$, respectively (DSI, 2012). In addition to those, the bulk modulus and density of the reservoir water are $2.07 \mathrm{MPa}$ and $999.18 \mathrm{~kg} \mathrm{~m}^{-3}$, respectively.

\subsection{Finite element model of Çine dam}

This study considers three-dimensional finite element model of Çine RCC dam (Fig. 9). In this model, if the height of the dam is indicated as " $H$ ", the foundation soil is extended as " $H$ " in the transverse river direction, downstream direction and gravity direction. Besides, foundation soil and reservoir water model is extended as " $3 H$ " in the upstream direction. The height of the reservoir water is considered as the dam height. The solid finite elements (Solid45) used in the 
Table 1. The material properties of Çine RCC dam (DSI, 2012).

\begin{tabular}{lrrr}
\hline & \multicolumn{3}{c}{ Material Properties } \\
\cline { 2 - 4 } & $\begin{array}{r}\text { Modulus of } \\
\text { Elasticity (MPa) }\end{array}$ & $\begin{array}{r}\text { Poisson's } \\
\text { Ratio }\end{array}$ & $\begin{array}{r}\text { Mass Density } \\
\left(\mathrm{kg} \mathrm{m}^{-1}\right)\end{array}$ \\
\hline Concrete (Dam) & $3.00 \times 10^{4}$ & 0.20 & 2530 \\
Rock (Upper Foundation Soil) & $2.80 \times 10^{4}$ & 0.19 & 2900 \\
Rock (Lower Foundation Soil) & $2.50 \times 10^{4}$ & 0.18 & 2800 \\
\hline
\end{tabular}

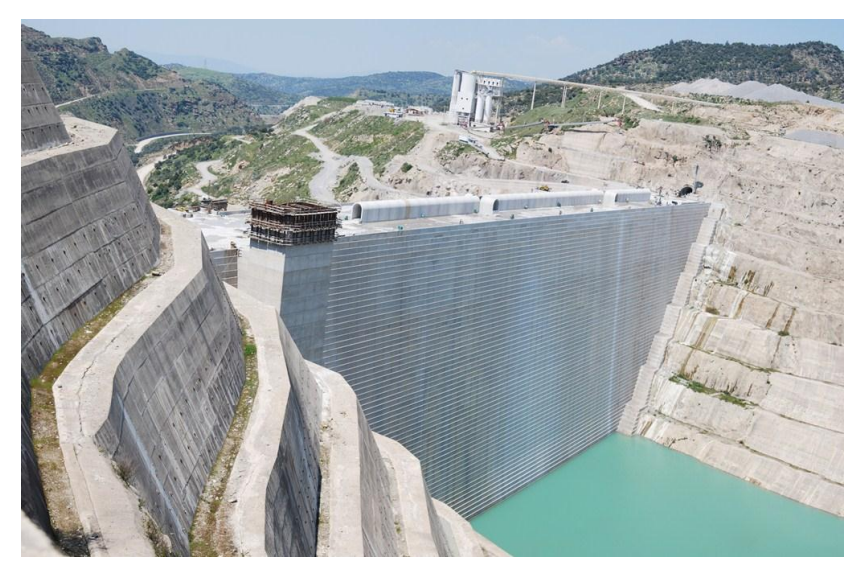

a) Upstream face.

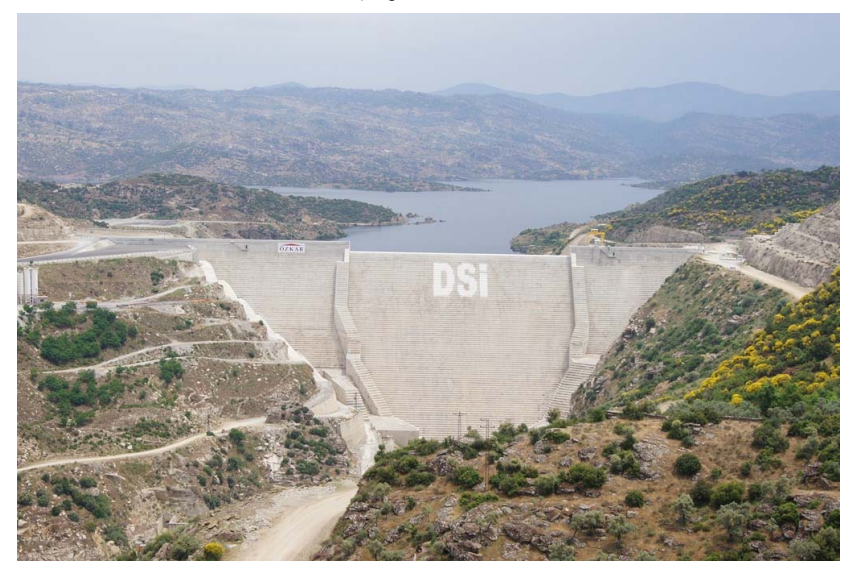

b) Downstream face.

Fig. 7. The view of the Çine RCC dam (DSI, 2012).

analysis have four nodes and $2 \times 2 \times 2$ integration points; the fluid finite elements (Fluid80) have four nodes and $1 \times 1 \times 1$ integration point. Fluid and solid element matrices are computed using the Gauss numerical integration technique (Wilson and Khalvati, 1983).

In the finite element model, RCC dam body has 850 ; lower foundation soil has 6444 , and upper foundation soil has 4896 solid finite elements. Besides, reservoir water has 1890 fluid finite elements. In addition to this, 35 contacttarget element pair in I-II Block interface, 35 contacttarget element pair in II-III Block interface, 30 contact and

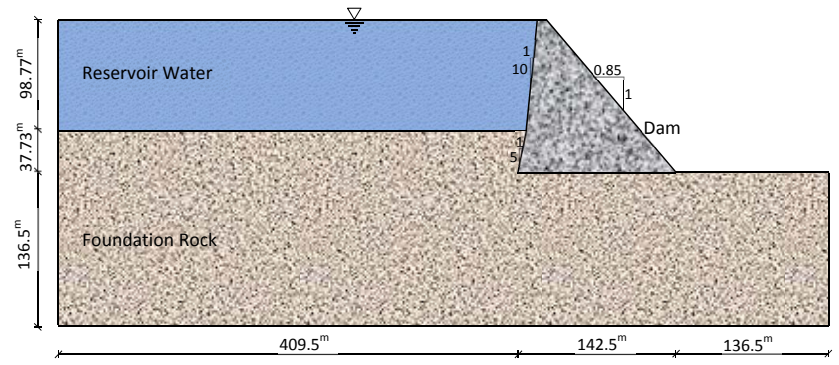

a) The middle cross section and dimensions.

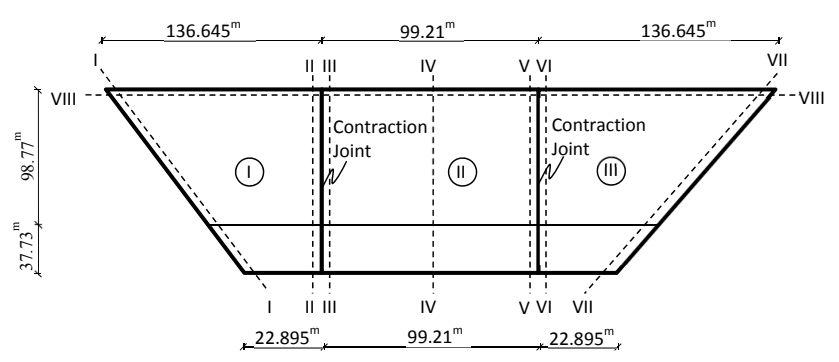

b) The front view, blocks, contraction joints, sections and dimensions.

Fig. 8. The views and dimensions of the Çine RCC dam (DSI, 2012).

96 target elements in dam-foundation soil (base) interface, 18 contact-target element pair in dam-foundation (upstream face) interface, 50 contact and 160 target elements in damfoundation (left valley) interface, and 50 contact and 160 target elements in dam-foundation (right valley) interface are defined to model interaction considering friction. Besides, 108 contact-target element pair in reservoir water-foundation (bottom) interface, 126 contact-target element pair in reservoir water-foundation (left valley) interface, 126 contacttarget element pair in reservoir water-foundation (right valley) interface, and 126 contact-target element pair in reservoir water-dam interface are defined to model fluid-structure and fluid-foundation interaction. In these interfaces, the use of the contact-target element pairs maintains equal displacements between the opposite nodes in the normal direction to the interface. In the finite element model, solid finite elements have a total of 14730 nodal points, and fluid finite elements have 2432 nodal points. There are three degrees of freedom in each node. 


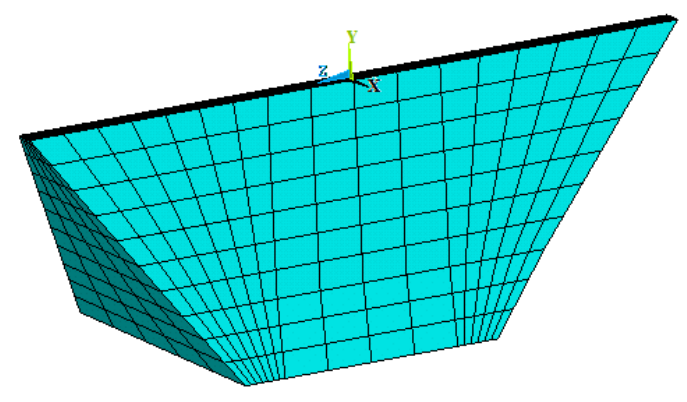

a) Dom body.

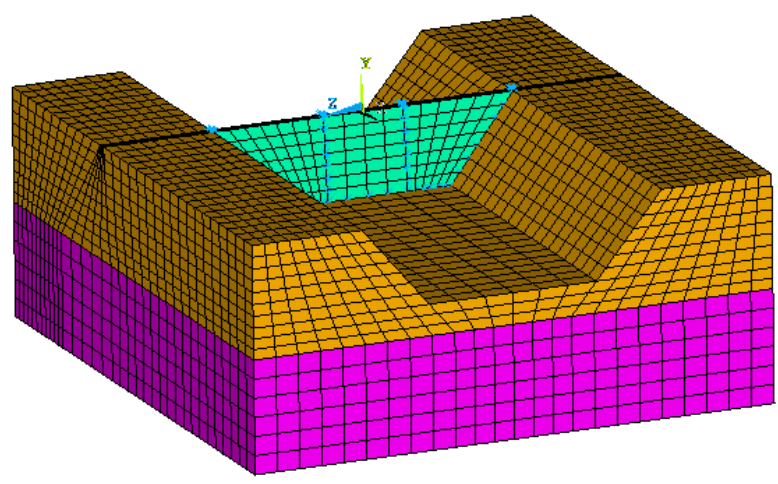

b) Dam-foundation interaction in empty reservoir case.

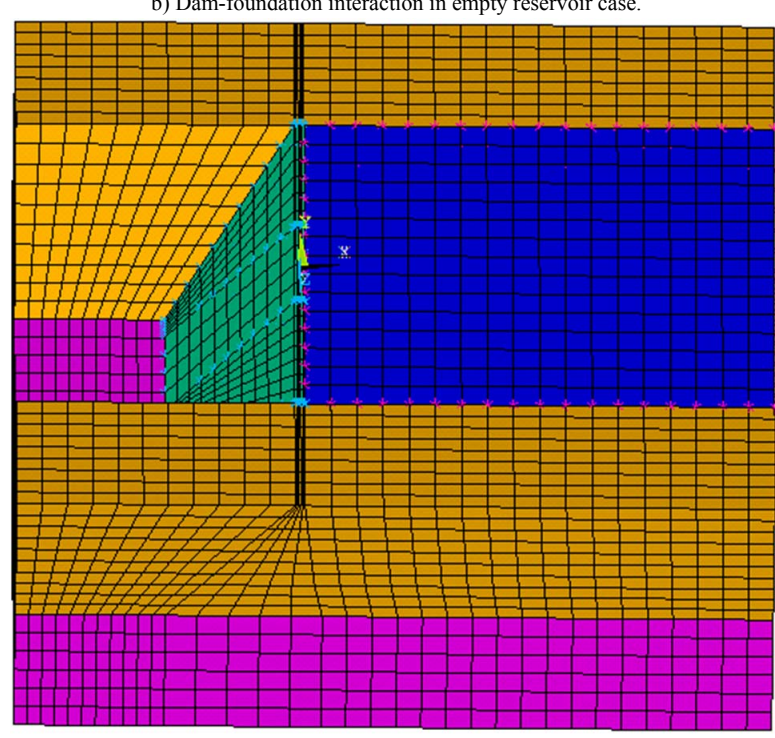

c) Dam-foundation-reservoir interaction in full reservoir case.

Fig. 9. The finite element model of the Çine RCC dam.

In the finite element model, first of all, fixed boundary condition is considered at foundation soil boundaries, and roller-supported boundary condition is considered at reservoir boundaries as initial condition. In this case, static analysis is performed under gravity effect in empty reservoir case, and in addition to this, hydrostatic pressure is also considered in full reservoir case. After the initial loading condition, which is gravity load and hydrostatic pressure, fixed and roller-supported boundary conditions are released. Afterward, viscous dampers are defined in the finite element model boundaries to consider infinite boundary condition. Thereby, zero length damper elements (Combin14) are used in three directions in solid boundaries and one direction in fluid boundaries. A total of 7938 viscous damper elements are defined in the foundation soil boundaries in " $\mathrm{X}$ ", " $\mathrm{Y}$ " and "Z" direction. For this purpose, 2646 nodal points are defined. Therefore, two dampers in tangential direction and one damper in axial direction are defined in the nodal points, which have the same coordinates. However, viscous dampers are defined in only axial direction for reservoir water. Each constant of the viscous dampers is calculated and defined considering effective material properties and the volume of the each related nodal points separately. Viscous damper constants are calculated as proposed by Lysmer and Kuhlemeyer (1969).

\subsection{Structural connections in a RCC dam}

The presence of transverse contraction joints is beneficial for most RCC dams. The reduction in mixing water and reduced temperature rise resulting from the rapid placement rate and lower lift heights result in low potential for cracking. If the site configuration and foundation conditions potentially restrain the dam and, in addition, the dam will be constructed in an earthquake zone, contraction joints should be considered and designed in a RCC dam to control cracking. If contraction joints are properly designed and installed, they will not interfere or complicate the continuous placement operation of RCC (USACE, 1995).

The contraction joints in the RCC dam, dam-foundation and dam-valley interfaces can be indicated as structural connections in a RCC dam. Structural connections are generally modeled with welded and friction contact. Welded contact is realized as defining common nodal points in the contact interface. Therefore, stress or displacement transmission is not possible in this connection type, because the same displacement and common stress components in the related node of adjacent elements are obtained. However, friction contact is represented by interface or contact elements. Interface elements, which are eight or sixteen-noded finite elements for three-dimensional systems, provide friction behavior by defined transverse shear stiffness. In the other case, six or eightnoded contact element pairs are defined between the surfaces of volumes. In this study, 2-D/3-D node-to-surface contact elements (Conta175) and 3-D target elements are used. These elements are capable of Coulomb friction, shear stress friction or user defined friction.

If the adjacent medias have two different material properties, their connection should be formed with different nodes at interface. If a RCC dam is taken into consideration, RCC dam block interfaces, dam-foundation (bottom and upstream) and dam-valley interfaces can be regarded. Therefore, friction defined in the related interfaces can provide 
more realistic results. In this study, normal and tangential stiffness on the interfaces are set to be $K_{n}=240 \mathrm{GPa} \mathrm{m}^{-1}$ and $K_{t}=24 \mathrm{GPa} \mathrm{m}^{-1}$, respectively. In this study, standard contact model is considered in the interface between dam and foundation in upstream side. This model allows the separation and sliding of the surfaces. However, no separation contact model is considered in all of the other connections. This model allows only the sliding of the surfaces. But, in full reservoir case, no separation contact model is used for all connections that also include fluid-foundation and fluidstructure interaction.

The stiffness matrix for contact element in three various states are written as the following:

1. Joint is numerically closed, and there is no sliding between two adjacent nodes:

$$
[\mathbf{K}]=\left[\begin{array}{cccccc}
K_{n} & 0 & 0 & -K_{n} & 0 & 0 \\
0 & K_{t} & 0 & 0 & -K_{t} & 0 \\
0 & 0 & K_{t} & 0 & 0 & -K_{t} \\
-K_{n} & 0 & 0 & K_{n} & 0 & 0 \\
0 & -K_{t} & 0 & 0 & K_{t} & 0 \\
0 & 0 & -K_{t} & 0 & 0 & K_{t}
\end{array}\right]
$$

2. Joint is numerically closed, but two nodes are sliding on each other:

$$
[\mathbf{K}]=\left[\begin{array}{cccccc}
K_{n} & 0 & 0 & -K_{n} & 0 & 0 \\
0 & 0 & 0 & 0 & 0 & 0 \\
0 & 0 & 0 & 0 & 0 & 0 \\
-K_{n} & 0 & 0 & K_{n} & 0 & 0 \\
0 & 0 & 0 & 0 & 0 & 0 \\
0 & 0 & 0 & 0 & 0 & 0
\end{array}\right]
$$

3. Joint is numerically open. In this situation all stiffness matrix arrays must be zero, because there is no contact between two nodes:

$$
[\mathbf{K}]=[0]_{6 \times 6}
$$

Two contacting surfaces can bear shear stress up to a certain extent across their interfaces before sliding in the basic Coulomb friction law. This is named "stick" case. Coulomb friction model is defined with " $\tau$ " equivalent shear stress, in which sliding begins as a part of " $p$ " contact pressure. This stress is

$\tau_{\lim }=\mu p+c$

where, $\tau_{\text {lim }}$ is limit shear stress, “ $\mu$ " is friction coefficient and " $c$ " is contact cohesion. Once equivalent shear stress exceeds $\tau_{\text {lim }}$, the contact and target surfaces move relatively in respect of each other. This is named "sliding". Friction coefficient of " 0 " refers to the frictionless contact problems. However, friction coefficient is " 1 " for bonded surfaces.

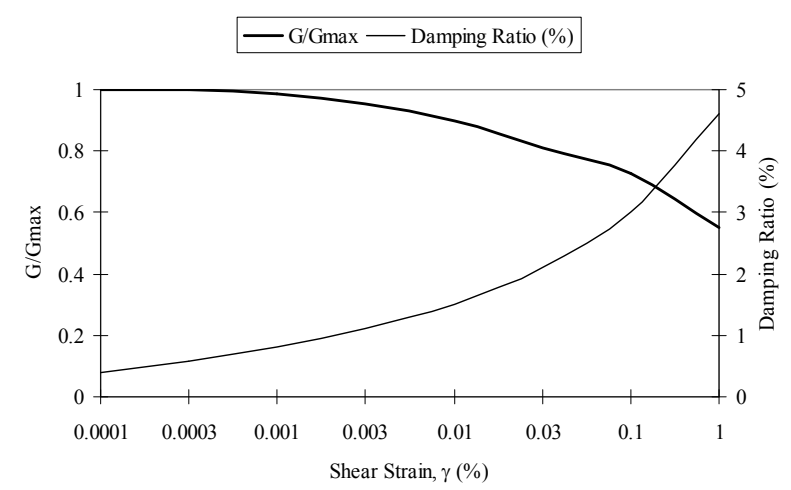

Fig. 10. Normalized shear modulus-shear strain and damping ratio relationships for rocks (Schnabel et al., 1972).

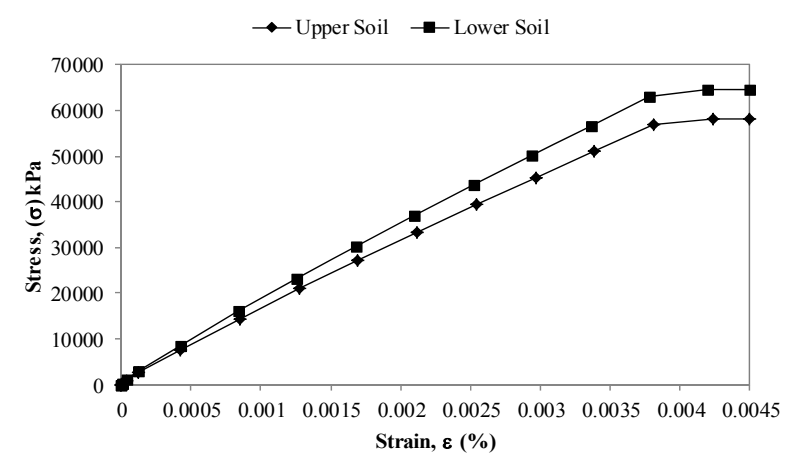

Fig. 11. The uniaxial compressive stress-strain relationship for foundation rock.

\subsection{Non-linear behavior of RCC dam}

In the materially non-linear analyses, the bilinear kinematic hardening material model is used for concrete of the dam body. For this purpose, the yield stress is considered as $1300 \mathrm{kPa}$ and Tangent modulus is used as $180277 \mathrm{kPa}$. This material model is recommended for general small-strain use for materials that obey von Mises yield criterion (Ansys, 2012).

Non-linear response of the foundation soil is determined by the multilinear kinematic hardening model. In this method, uniaxial stress-strain curve of the non-linear material is required. This curve can be determined by shear modulus-shear strain relationship for rock materials. Shear modulus-shear strain relation for rock soils obtained from experimental studies by Schnabel et al. (1972) is used for rock foundation soil (Fig. 10). Using these curves, the uniaxial stress-strain curves for the rock layers in the foundation soil are determined (as shown in Fig. 11). 


\section{Numerical analysis}

In this study, three-dimensional behavior of a RCC dam is investigated under strong ground motions for empty and full reservoir cases. In the numerical solutions, firstly, the gravity effect and hydrostatic pressure are considered as initial condition due to common boundary conditions. After the static effects, viscous boundary condition is replaced. Then, linear and materially non-linear time-history analyses are carried out for each direction of the 1999 Düzce earthquake accelerograms (PEER, 2012). Geometrical non-linearity is considered in both materially linear and non-linear analyses. According to earthquake analysis, maximum horizontal displacements and maximum principal stress components are presented.

\subsection{Strong ground motion effects}

This study investigates the earthquake response of Çine RCC Dam subjected to strong ground motion. Empty and full reservoir cases are taken into account in the numerical solutions. The east-west, north-south and also vertical components of the 1999 Düzce earthquake are utilized in analyses (Fig. 12). Earthquake analyses are performed during $15.00 \mathrm{~s}$ (Fig. 12) and use acceleration record, which is available at the PEER Strong Motion Database (PEER, 2012). The time interval of the acceleration record is $0.01 \mathrm{~s}$. Linear and non-linear time-history analyses are performed using Ansys (2012). In the non-linear time-history analyses, the time interval is used as 0.005 in empty reservoir case, second and $0.001 \mathrm{~s}$ in full reservoir case by linear interpolation of the accelerograms. Rayleigh damping is used in time-history analysis. Therefore, first, six vibration frequencies are considered to calculate Rayleigh damping constants using initial boundary conditions (Rayleigh and Lindsay, 1945; Chopra, 1996). Besides, Newmark algorithm is employed in numerical solutions.

\subsection{Earthquake response of Çine RCC dam}

This study presents earthquake behavior of Çine RCC dam considering east-west, north-south and vertical components of 1999 Düzce earthquake. Accelerograms of the earthquake are applied on the settled condition of the dam. According to linear and non-linear time-history analyses, maximum horizontal displacements in upstream-downstream direction and maximum principal stress components in the selected RCC dam are presented.

\subsubsection{Horizontal displacements}

Horizontal displacements of the RCC dam under strong ground motion effects are shown in Figs. 13-17 for I-I, IVIV, VII-VII and VIII-VIII sections.

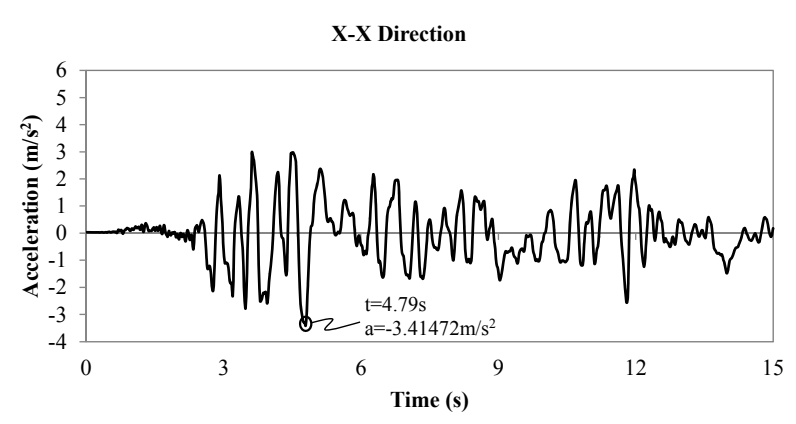

a) East-west component.
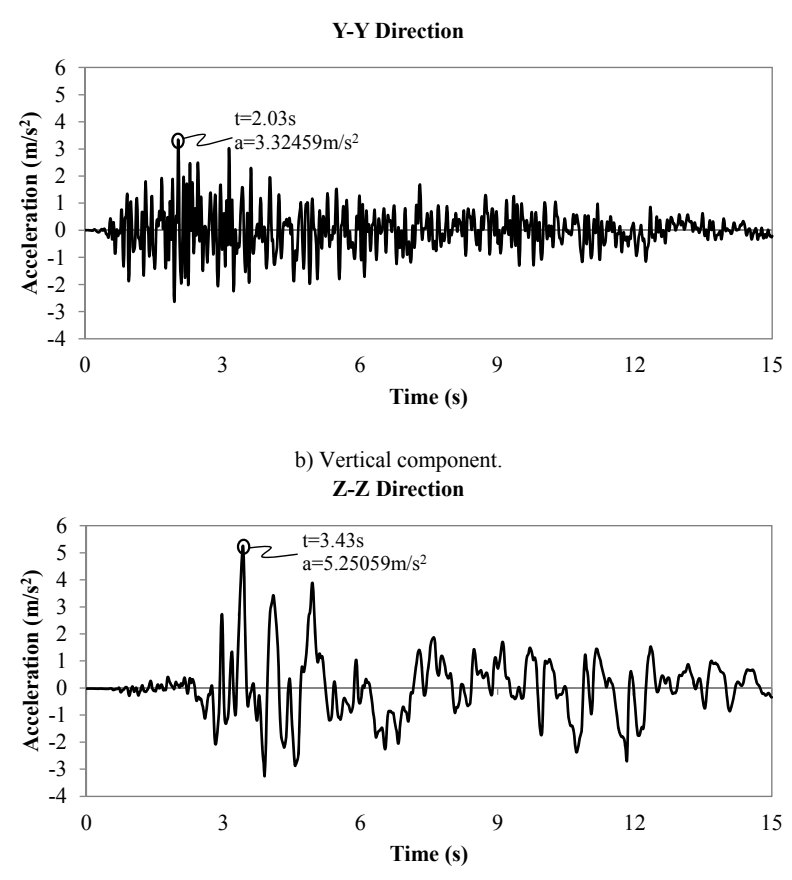

c) North-south component.

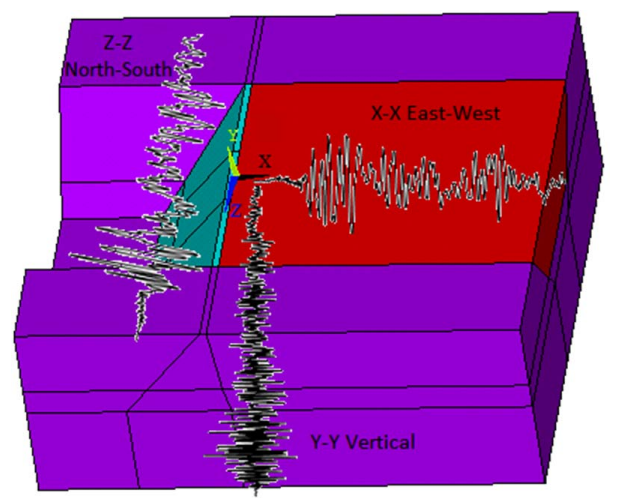

d) Applied earthquake record directions in RCC dam model.

Fig. 12. 1999 Düzce earthquake records. 


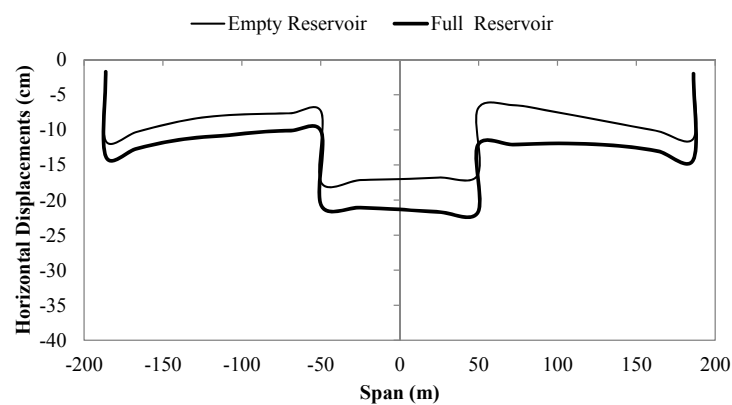

a) The maximum horizontal displacements in downstream direction according to linear analysis.

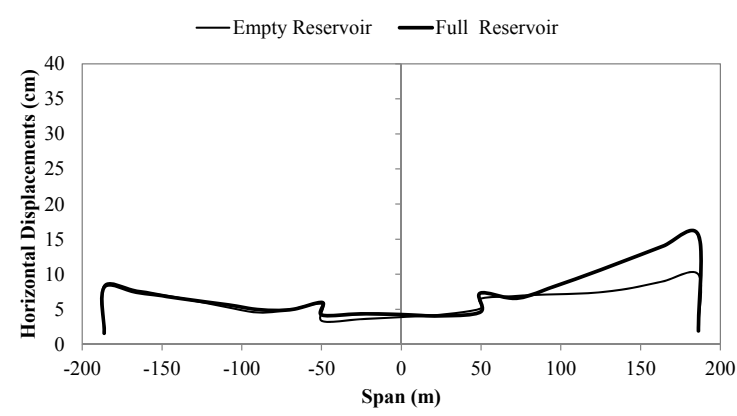

b) The maximum horizontal displacements in upstream direction according to linear analysis.

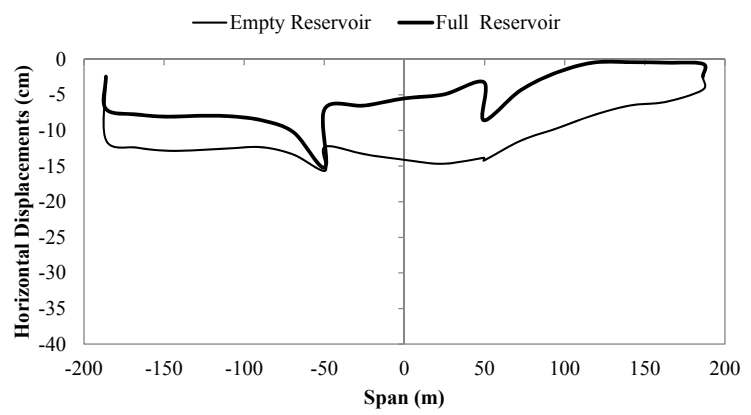

c) The maximum horizontal displacements in downstream direction according to non-linear analysis.

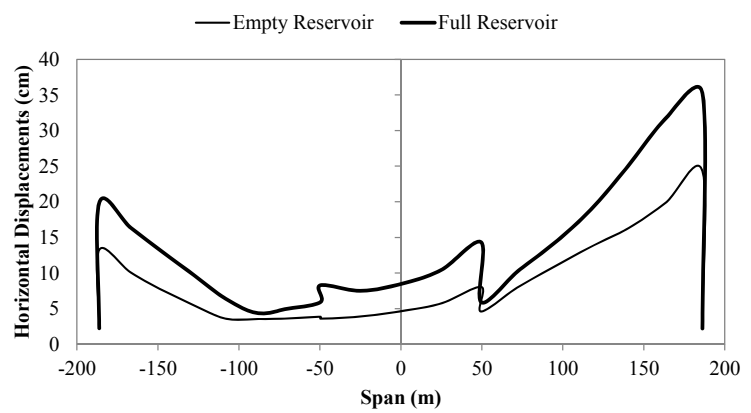

d) The maximum horizontal displacements in upstream direction according to non-linear analysis.

Fig. 13. The maximum horizontal displacements at crest.

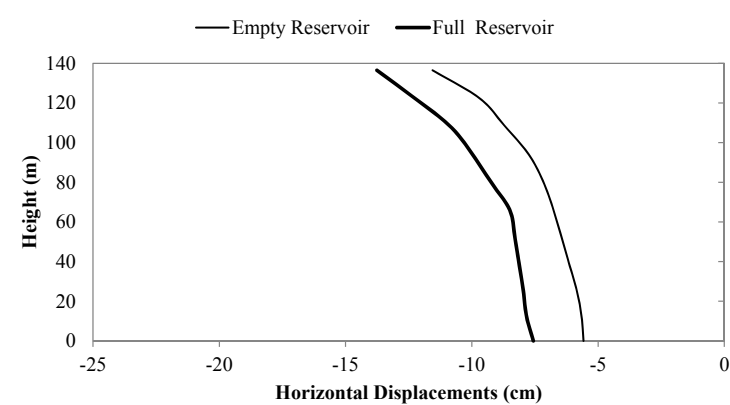

a) The maximum horizontal displacements in downstream direction according to linear analysis.

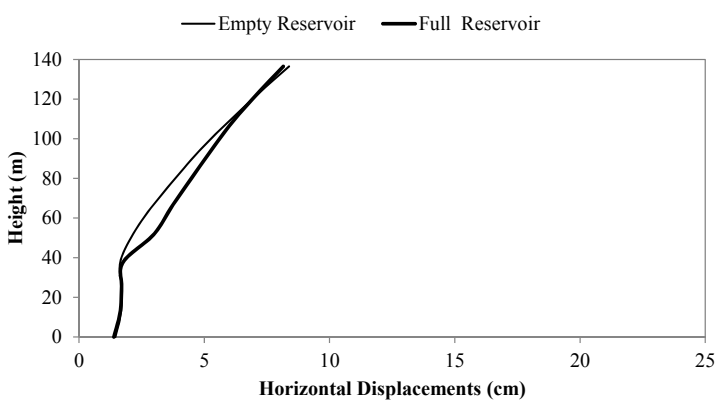

b) The maximum horizontal displacements in upstream direction according to linear analysis.

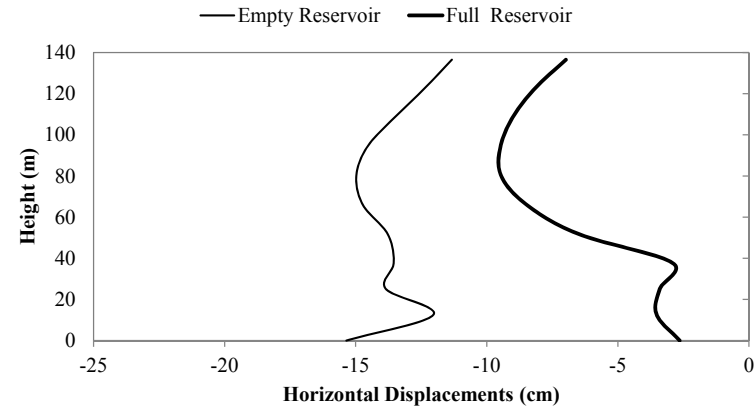

c) The maximum horizontal displacements in downstream direction according to non-linea analysis.

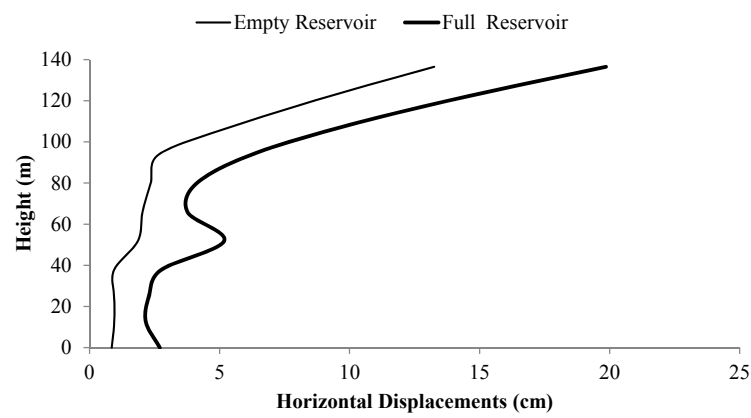

d) The maximum horizontal displacements in upstream direction according to non-linear analysis.

Fig. 14. The maximum horizontal displacements in I-I section. 


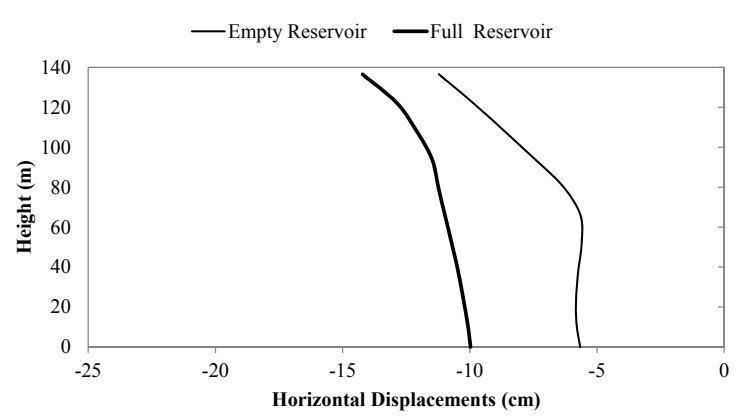

a) The maximum horizontal displacements in downstream direction according to linear analysis.

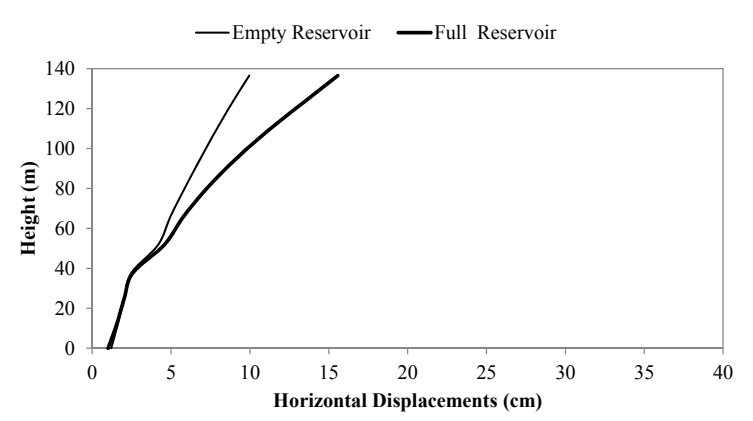

b) The maximum horizontal displacements in upstream direction according to linear analysis.

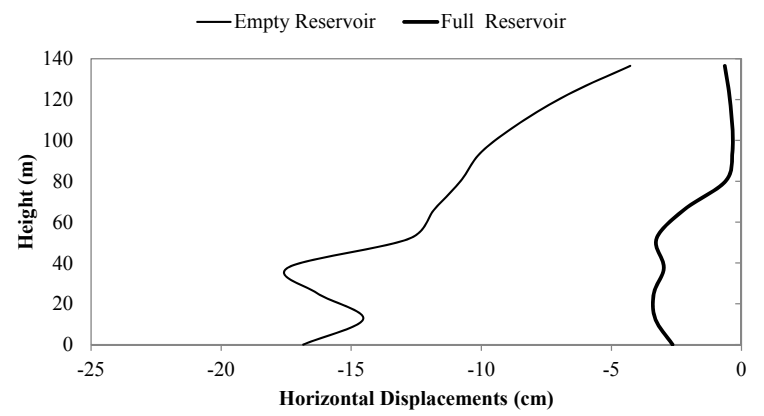

c) The maximum horizontal displacements in downstream direction according to non-linear analysis.

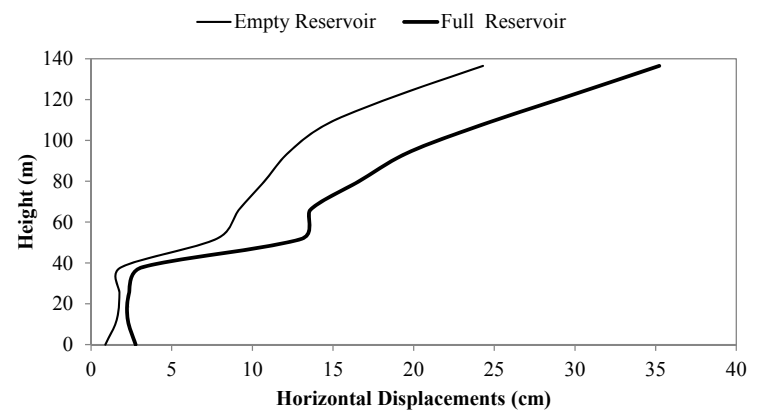

d) The maximum horizontal displacements in upstream direction according to non-linear analysis.

Fig. 15. The maximum horizontal displacements in VII-VII section.

\section{Horizontal displacements in VIII-VIII section}

The horizontal displacements of the RCC dam in VIII-VIII section are shown in Fig. 13 for both reservoir conditions according to materially linear and non-linear analyses.

Linear time-history analyses indicate that hydrodynamic pressure of the reservoir increases the maximum horizontal displacements in upstream and downstream directions at crest.

According to non-linear analyses, maximum horizontal displacements are greater in empty reservoir case in downstream direction. However, maximum horizontal displacements appear in full reservoir case in upstream direction. In addition to this, the maximum horizontal displacement appears in III Block in upstream direction as $35.23 \mathrm{~cm}$ under hydrodynamic pressure. The main reason for the decrease of the horizontal displacements in full reservoir case in downstream direction is the high increase of the horizontal displacements in upstream direction due to non-linear response of the dam.

If materially linear and non-linear horizontal displacements at crest of the dam are compared, the maximum horizontal displacements obtained from the non-linear analysis are greater than ones obtained from the linear analysis.

\section{Horizontal displacements in I-I section}

The horizontal displacements of the RCC dam in I-I section are shown in Fig. 14 for both reservoir conditions according to materially linear and non-linear analyses.

Linear analyses suggest that hydrodynamic pressure increases the maximum horizontal displacements in each direction.

In case of the base displacements of the dam increase in downstream direction in empty reservoir case, they increase in upstream direction in full reservoir case. Although no separation contact condition is considered between dam and front foundation soil, this condition appears in full reservoir case because of the effect of the hydrodynamic pressure. But, relative horizontal displacements increase in each direction under hydrodynamic pressure.

As compared to materially linear and non-linear analyses, in the case that the horizontal displacements slightly decrease in downstream direction, a large increase appears in upstream direction. Besides, relative horizontal displacements increase in upstream direction for each reservoir condition.

\section{Horizontal displacements in VII-VII section}

The horizontal displacements of the RCC dam in VII-VII section are shown in Fig. 15 for both reservoir conditions according to materially linear and non-linear analyses.

Materially linear analyses denote that the maximum horizontal displacements appear in full reservoir case. The 


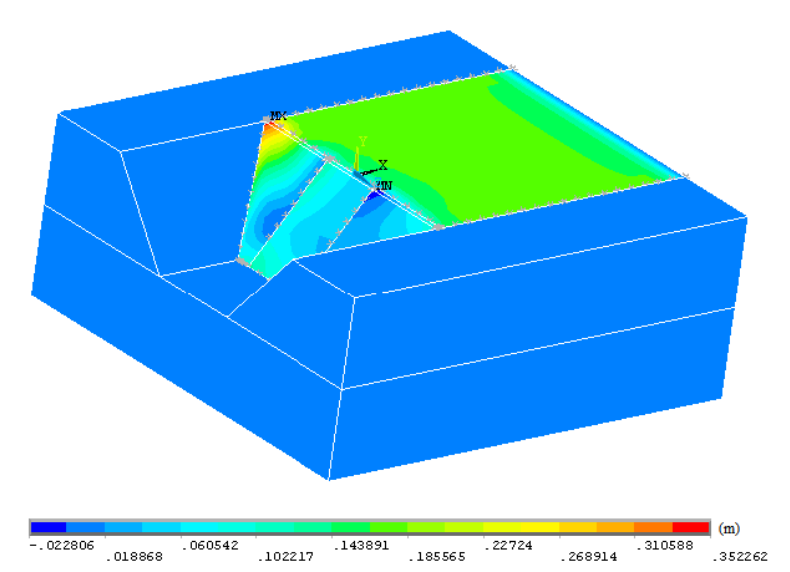

Fig. 16. The horizontal displacement contour diagram of the dam for $\mathrm{x}$-axis in second 10.55 .

increase of the displacements is more apparent in upstream direction.

According to non-linear analyses, maximum horizontal displacements did not occur in downstream direction, although base translation occurs. However, horizontal displacements take maximum values in upstream direction. In full reservoir case, maximum crest displacement occurs as $35.23 \mathrm{~cm}$ under hydrodynamic pressure. The contour diagram of the dam for the maximum horizontal displacement at crest is also shown in Fig. 16.

In the comparison of linear and non-linear analyses, the displacements increase due to materially non-linear response of the dam.

\section{Horizontal displacements in IV-IV section}

The horizontal displacements of the RCC dam in IV-IV section are shown in Fig. 17 for both reservoir conditions according to materially linear and non-linear analyses.

The horizontal displacements slightly increase in upstream direction under hydrodynamic pressure. However, relative horizontal displacements are close to each other, though base translation increases about $5 \mathrm{~cm}$ in full reservoir case in downstream direction.

Materially non-linear analyses suggest that relative horizontal displacements increase in full reservoir in each direction. Besides, base translation has maximum value as $16.5 \mathrm{~cm}$ in downstream direction in empty reservoir case. But, base translation is greater under hydrodynamics pressure in upstream direction.

As compared to materially linear and non-linear analyses, the relative horizontal displacements are greater when material non-linearity is considered in finite element model.

\section{Horizontal displacements during earthquake}

In this section, the maximum horizontal displacements are considered during earthquake for empty and full reservoir

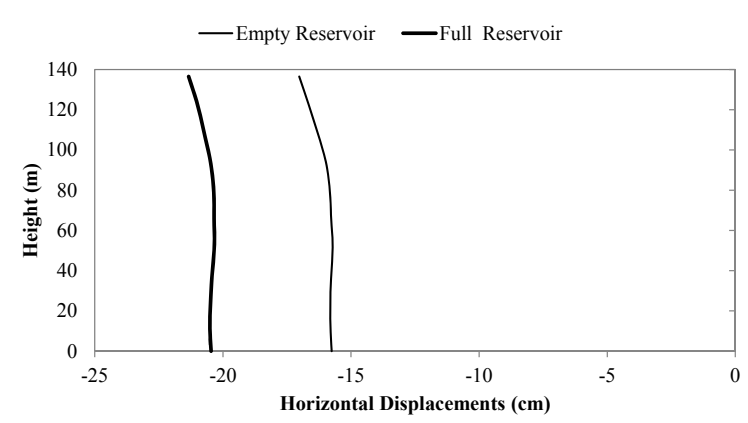

a) The maximum horizontal displacements in downstream direction according to linear analysis.

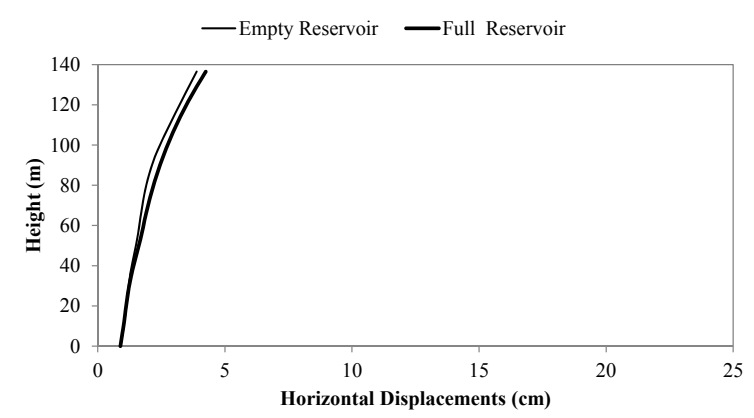

b) The maximum horizontal displacements in upstream direction according to linear analysis.

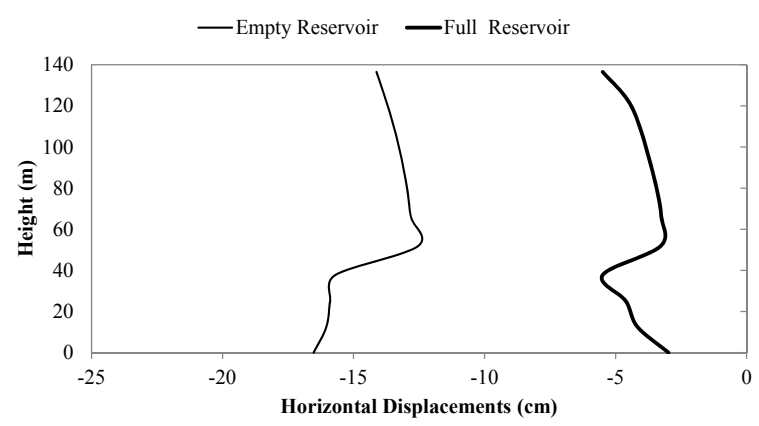

c) The maximum horizontal displacements in downstream direction according to non-linear analysis.

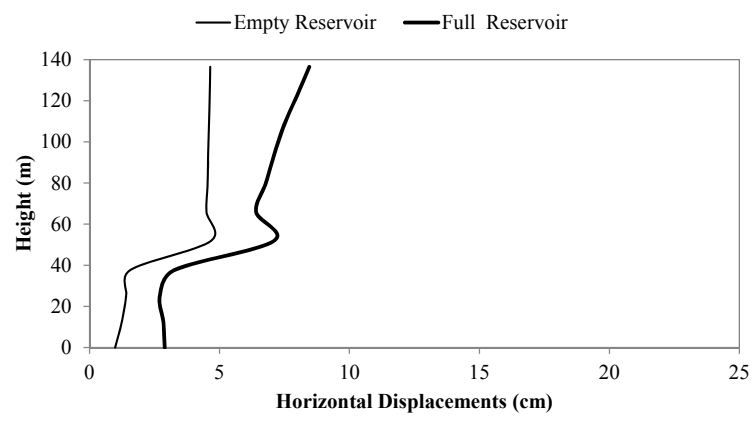

d) The maximum horizontal displacements in upstream direction according to non-linear analysis.

Fig. 17. The maximum horizontal displacements in IV-IV section. 
cases. The maximum horizontal displacements are selected between I-I and VIII-VIII. These are presented during earthquake in Fig. 18 for materially linear and non-linear analyses. According to Fig. 18, the horizontal displacements and oscillations are higher in full reservoir case due to hydrostatic and hydrodynamic pressure of reservoir water.

\subsubsection{Principal tensile and compressive stresses by height}

The principle stress components are shown along the dam height in I-I, II-II, III-III, IV-IV, V-V, VI-VI and VII-VII sections in Figs. 19-25.

\section{Principle stresses in I-I section}

The maximum principle tensile and compressive stresses of the RCC dam in I-I section, which is in upstream direction, are shown in Fig. 19 for both reservoir conditions according to materially linear and non-linear analyses.

Materially linear analyses show that though maximum principle stress values occur in the bottom of dam in empty reservoir case, the principle stress components clearly increase by dam height in full reservoir case.

According to materially non-linear analyses, the most critical principle stresses appear under hydrodynamic pressure.

As compared to materially linear and non-linear analyses, the principle stress components decrease in non-linear analyses.

\section{Principle stresses in II-II section}

The maximum principle tensile and compressive stresses of the RCC dam in II-II section, which is in upstream direction, are shown in Fig. 20 for both reservoir conditions according to materially linear and non-linear analyses.

Materially linear analyses indicate that hydrodynamic pressure increases the maximum principle stresses in linear analyses. This is clearly seen in principle tensile stresses.

Accordingly, the most critical principle stress components by the dam height occur under hydrodynamic pressure in materially non-linear time-history analyses.

As compared to materially linear and non-linear analyses, the principle stress components decrease in non-linear analyses.

\section{Principle stresses in III-III section}

The maximum principle tensile and compressive stresses of the RCC dam in III-III section, which is in upstream direction, are shown in Fig. 21 for both reservoir conditions according to materially linear and non-linear analyses.

The numerical analyses (including materially linear response of the dam) point out that the principle tensile and compressive stresses increase along the dam height by the effect of the reservoir water.

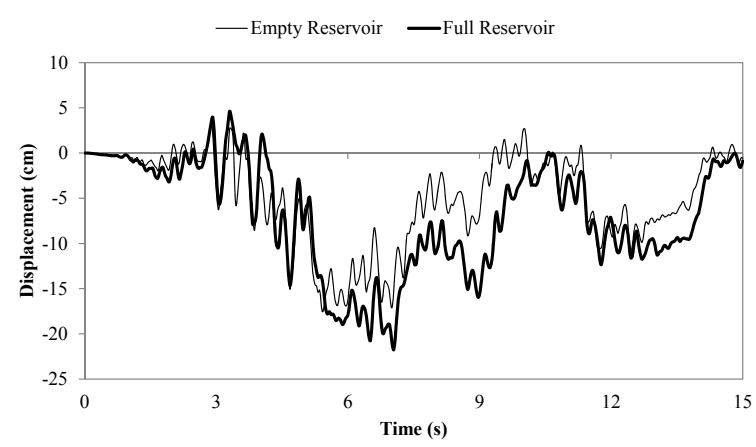

a) The maximum horizontal displacements in downstream direction according to linear analyses.

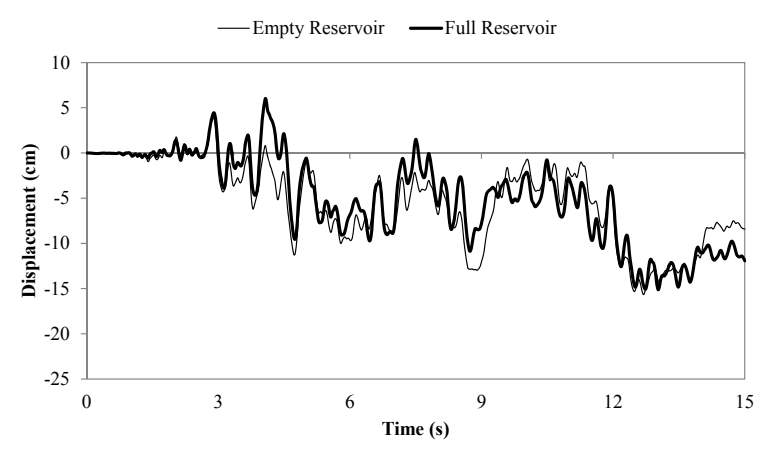

b) The maximum horizontal displacements in downstream direction according to non-linear analyses.

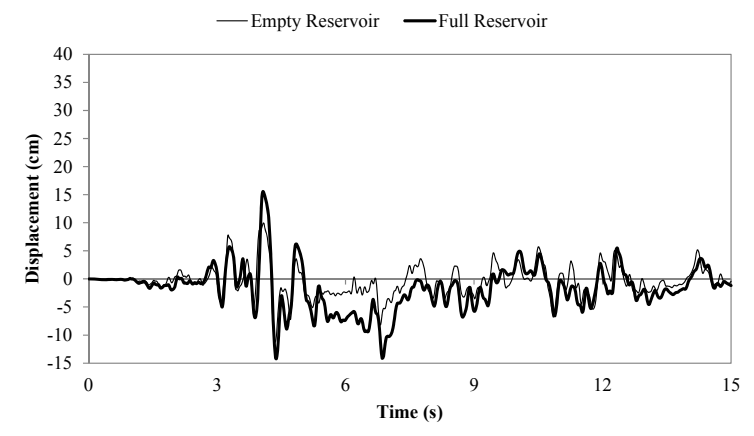

c) The maximum horizontal displacements in upstream direction according to linear analyses.

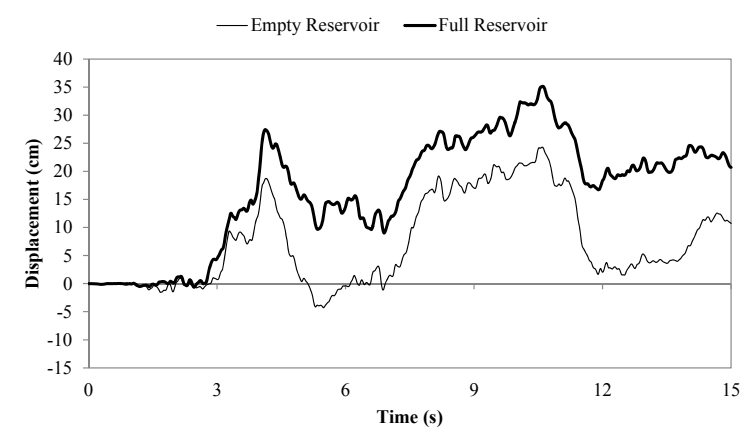

d) The maximum horizontal displacements in upstream direction according to non-linear analyses.

Fig. 18. The maximum horizontal displacements during earthquake. 


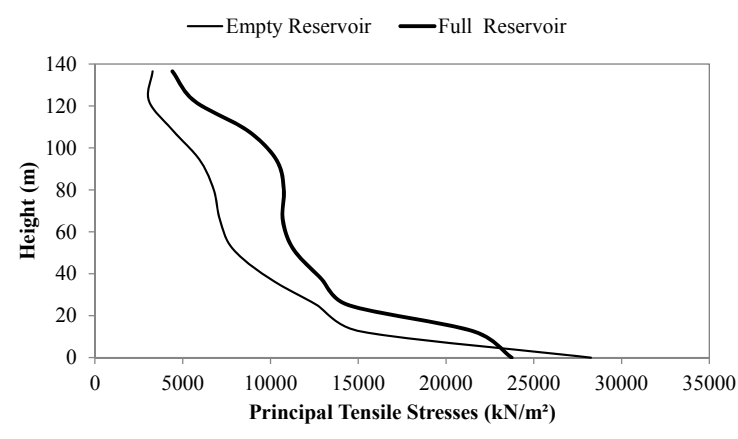

a) The maximum principle tensile stresses according to linear analysis.

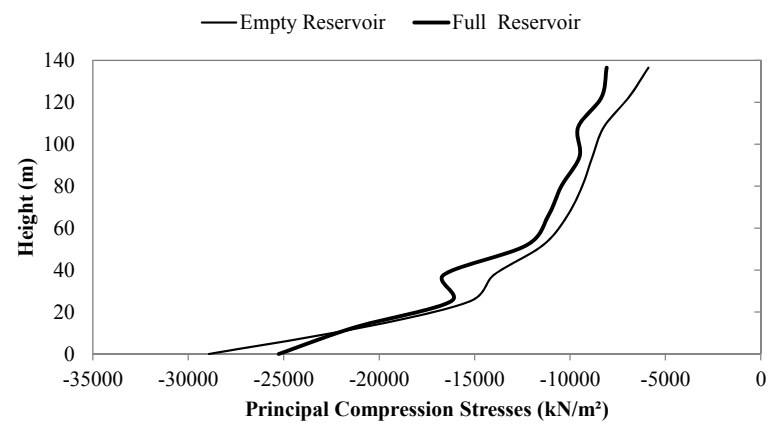

b) The maximum principle compressive stresses according to linear analysis. —Empty Reservoir —Full Reservoir

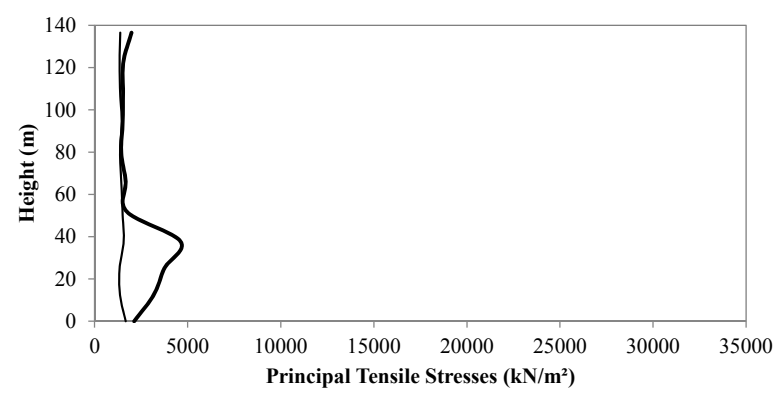

c) The maximum principle tensile stresses according to non-linear analysis.

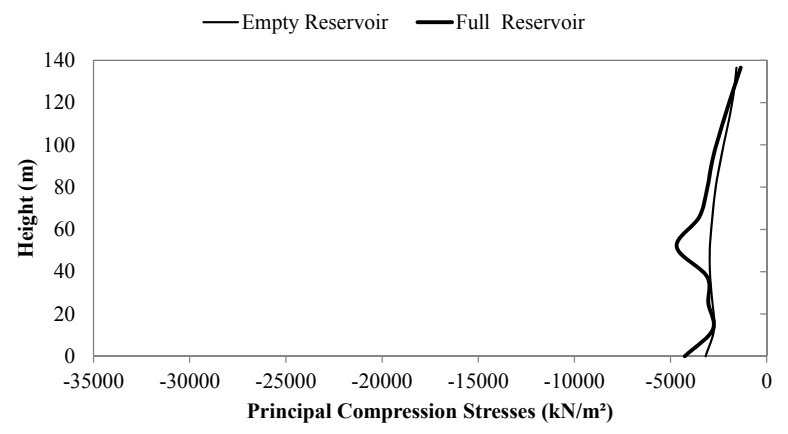

d) The maximum principle compressive stresses according to non-linear analysis.

Fig. 19. The maximum principle stress components in I-I section.

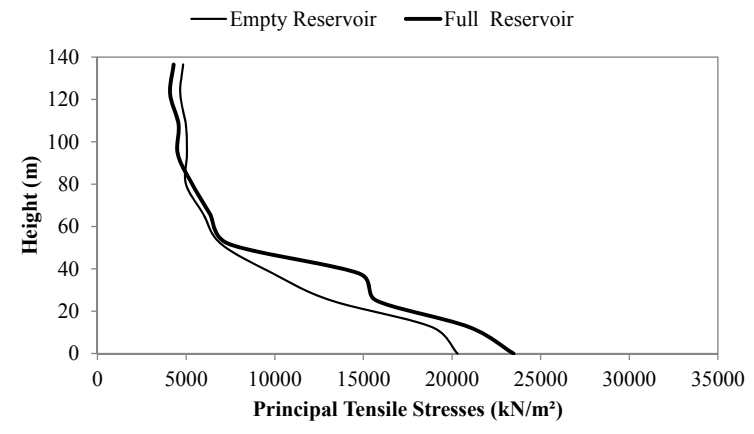

a) The maximum principle tensile stresses according to linear analysis.

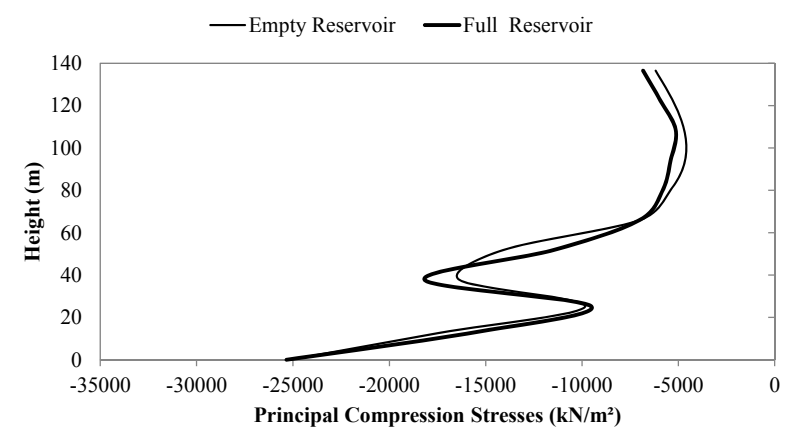

b) The maximum principle compressive stresses according to linear analysis.

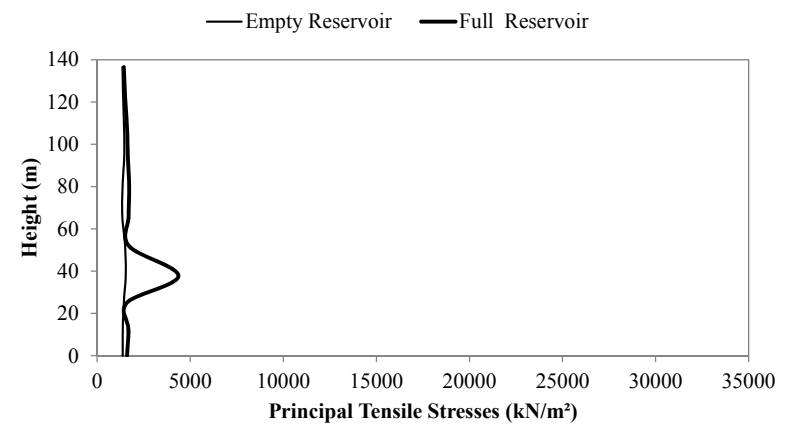

c) The maximum principle tensile stresses according to non-linear analysis.

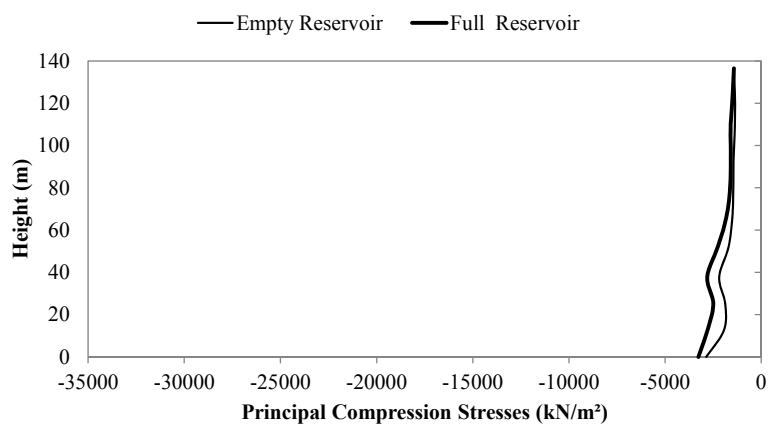

d) The maximum principle compressive stresses according to non-linear analysis.

Fig. 20. The maximum principle stress components in II-II section. 


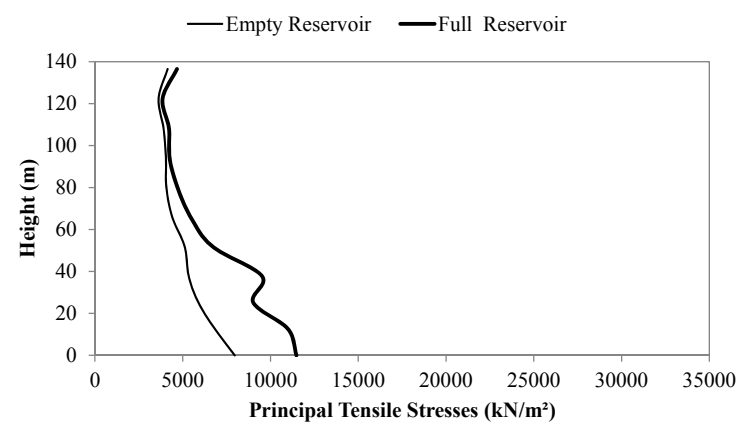

a) The maximum principle tensile stresses according to linear analysis.

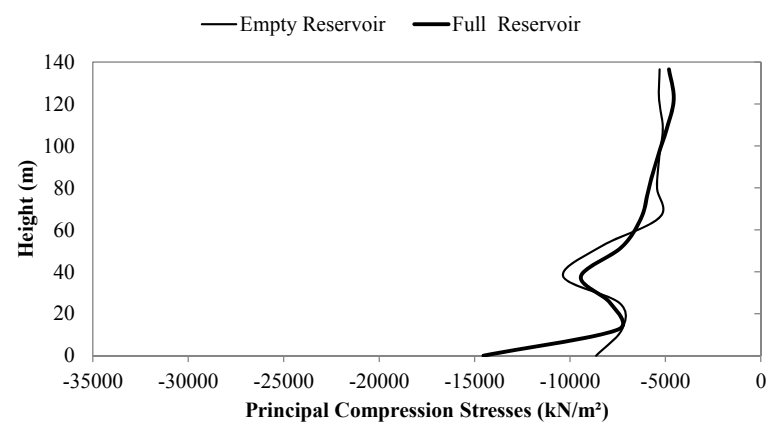

b) The maximum principle compressive stresses according to linear analysis.

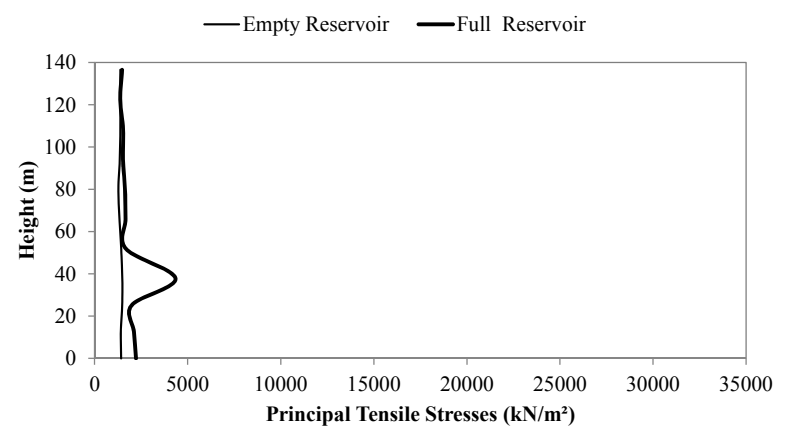

c) The maximum principle tensile stresses according to non-linear analysis.

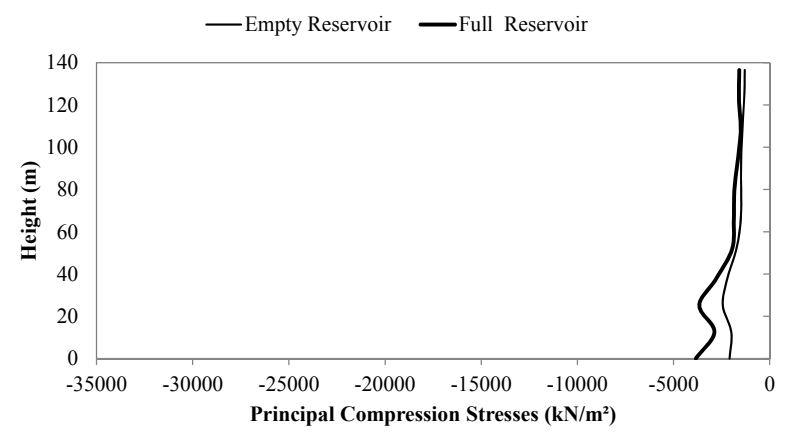

d) The maximum principle compressive stresses according to non-linear analysis.

Fig. 21. The maximum principle stress components in III-III section.
Similarly, the principle stress components increase under hydrodynamic pressure according to materially non-linear analysis.

As compared to materially linear and non-linear analyses, the principle tensile and compressive stresses take lower values in materially non-linear analyses.

\section{Principle stresses in IV-IV section}

The maximum principle tensile and compressive stresses of the RCC dam in IV-IV section, which is in upstream direction, are shown in Fig. 22 for both reservoir conditions according to materially linear and non-linear analyses.

Materially linear analyses suggest that the maximum principle stress components are obtained in full reservoir case. However, the principle compression stresses appear greater over $70 \mathrm{~m}$ of the dam in empty reservoir case.

If materially non-linear analyses are taken into consideration, the maximum principle tensile and compressive stresses occur under hydrodynamic pressure.

In the comparison of the materially linear and non-linear analyses, the principle stress components are lower according to non-linear analyses.

\section{Principle stresses in V-V section}

The maximum principle tensile and compressive stresses of the RCC dam in V-V section, which is in upstream direction, are shown in Fig. 23 for both reservoir conditions according to materially linear and non-linear analyses.

Linear time-history analysis results indicate that maximum principle stresses are greater in the lower part of the dam under hydrodynamic pressure.

According to materially non-linear analyses, the principle stress components increase in full reservoir case.

As compared to materially linear and non-linear analyses, the principle tensile and compressive stresses decrease in the non-linear analyses.

\section{Principle stresses in VI-VI section}

The maximum principle tensile and compressive stresses of the RCC dam in VI-VI section, which is in upstream direction, are shown in Fig. 24 for both reservoir conditions according to materially linear and non-linear analyses.

Materially linear analyses suggest that the maximum principle stress components are obtained in full reservoir case. However, the principle compression stresses appear greater over $70 \mathrm{~m}$ of the dam in empty reservoir case.

If materially non-linear analyses are taken into consideration, the maximum principle tensile and compressive stresses occur under hydrodynamic pressure.

In the comparison of the materially linear and non-linear analyses, the principle stress components are lower according to non-linear analyses. 


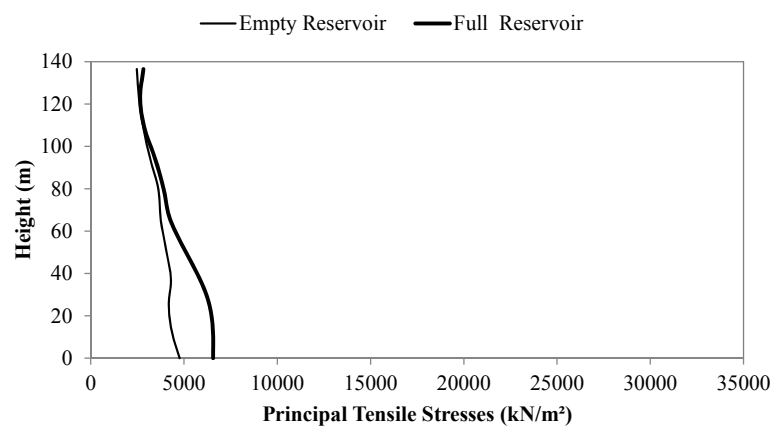

a) The maximum principle tensile stresses according to linear analysis.

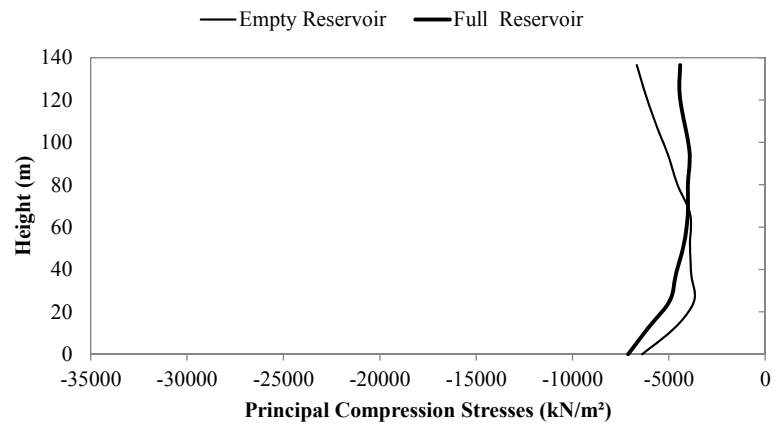

b) The maximum principle compressive stresses according to linear analysis. —Empty Reservoir —Full Reservoir

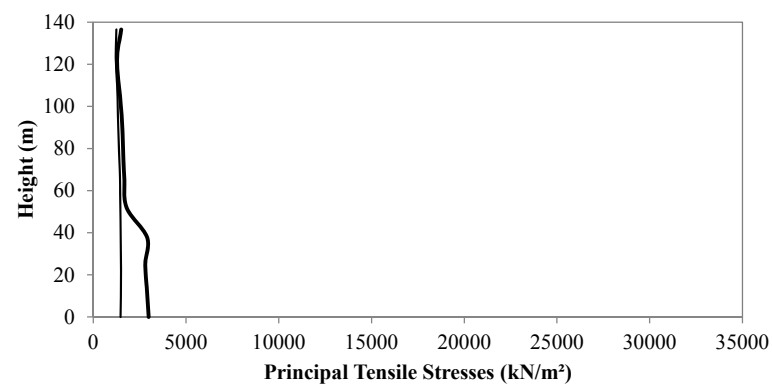

c) The maximum principle tensile stresses according to non-linear analysis.

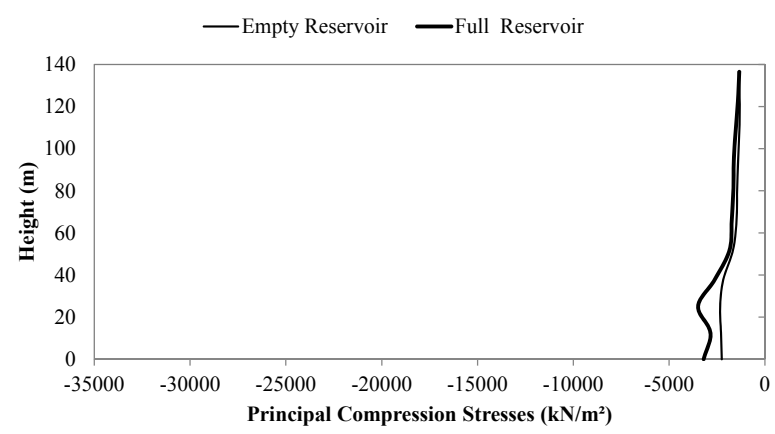

d) The maximum principle compressive stresses according to non-linear analysis.

Fig. 22. The maximum principle stress components in IV-IV section.

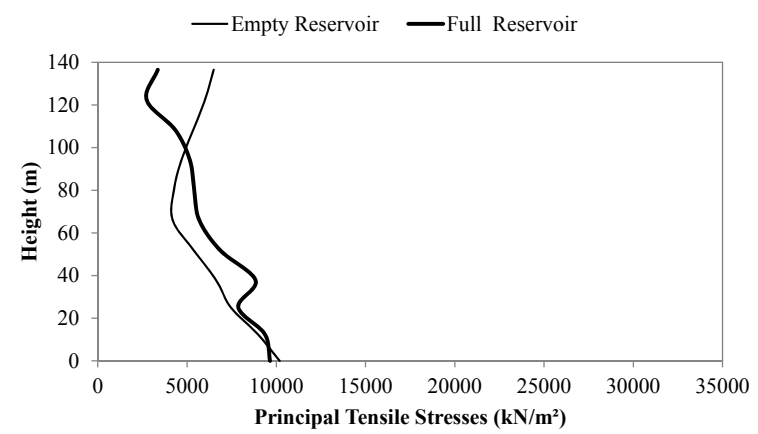

a) The maximum principle tensile stresses according to linear analysis.

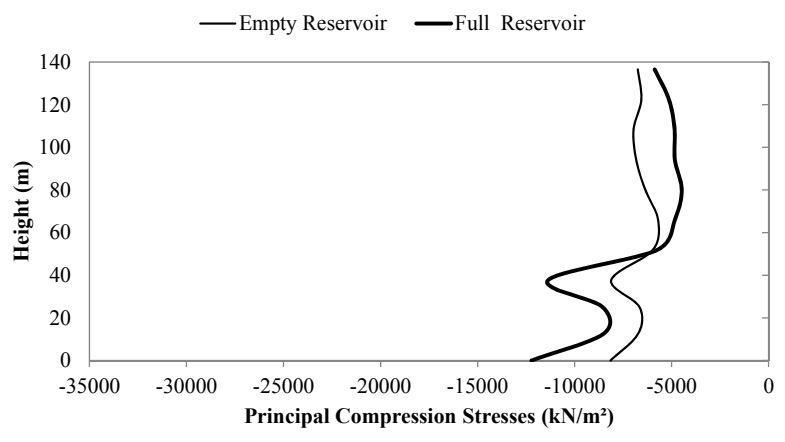

b) The maximum principle compressive stresses according to linear analysis.

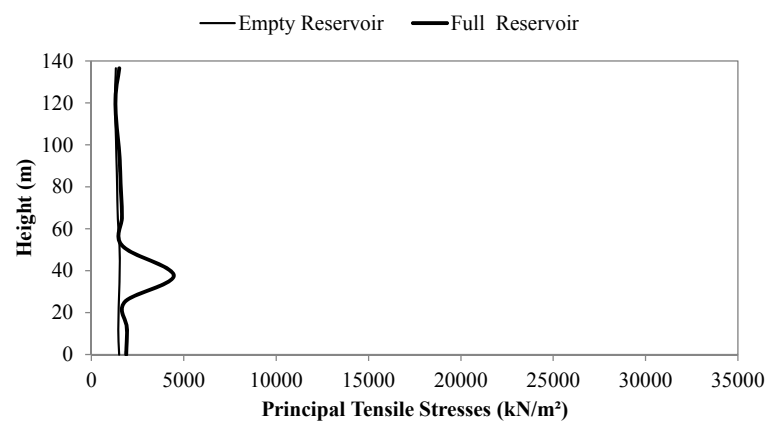

c) The maximum principle tensile stresses according to non-linear analysis

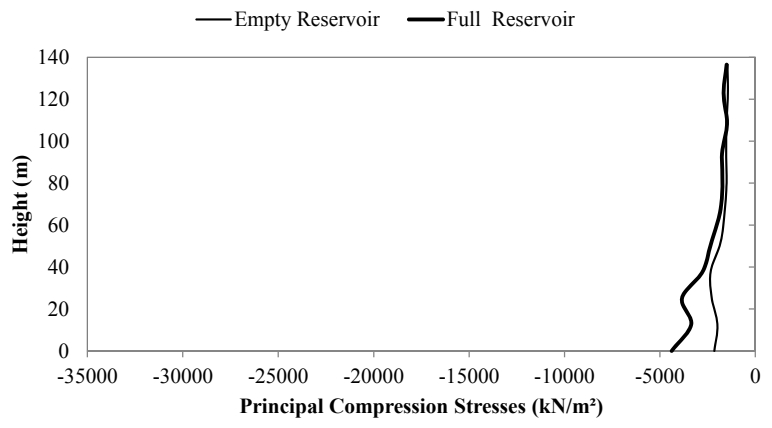

d) The maximum principle compressive stresses according to non-linear analysis.

Fig. 23. The maximum principle stress components in V-V section. 


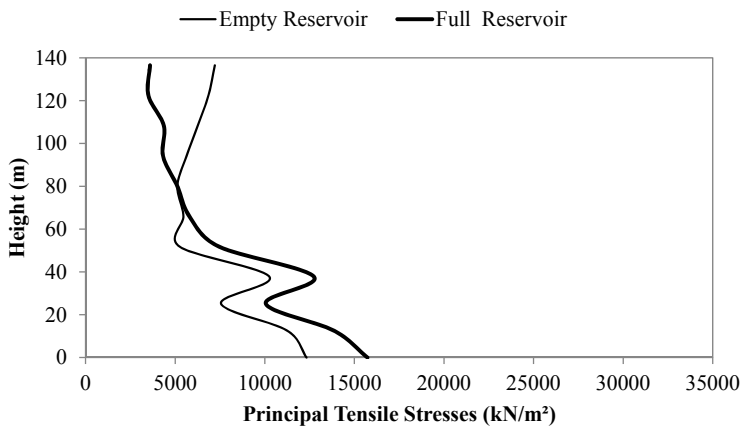

a) The maximum principle tensile stresses according to linear analysis.

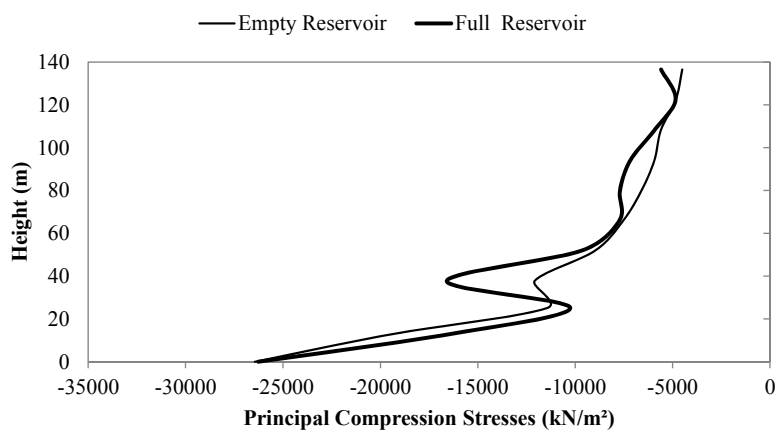

b) The maximum principle compressive stresses according to linear analysis. —Empty Reservoir —Full Reservoir

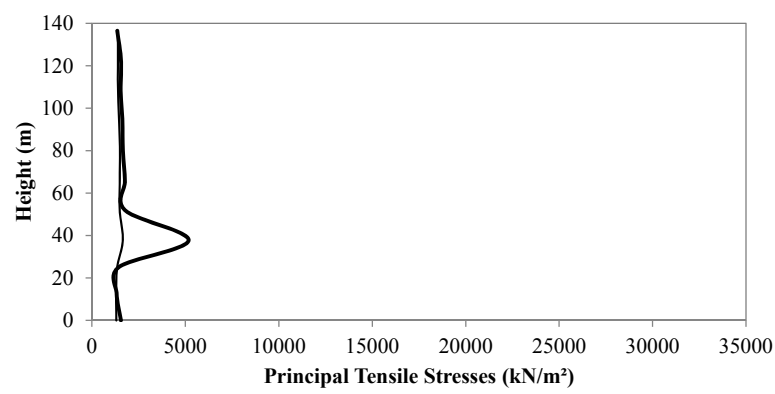

c) The maximum principle tensile stresses according to non-linear analysis.

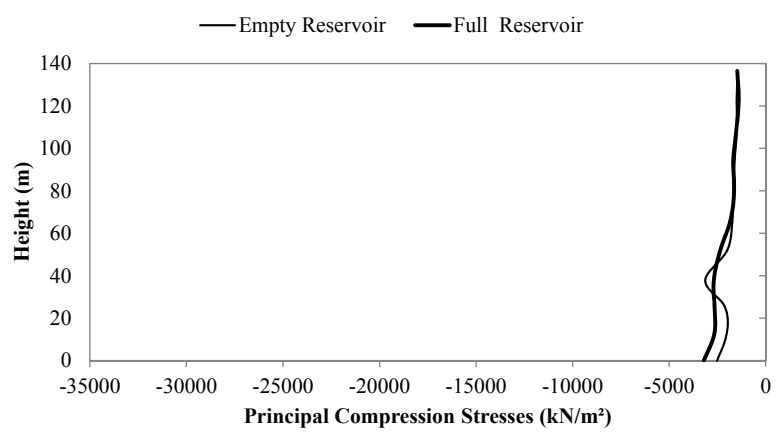

d) The maximum principle compressive stresses according to non-linear analysis.

Fig. 24. The maximum principle stress components in VI-VI section.

\section{Principle stresses in VII-VII section}

The maximum principle tensile and compressive stresses of the RCC dam in VII-VII section, which is in upstream direction, are shown in Fig. 25 for both reservoir conditions according to materially linear and non-linear analyses.

In the linear numerical analyses, the maximum principle compressive stresses occur in empty reservoir case near the base of the dam. But, principle compressive stresses increase by the effect of the hydrodynamic pressure over the $30 \mathrm{~m}$ from the bottom of the dam. In addition to this, the maximum principle tensile stresses appear in full reservoir case near the base of the dam.

According to materially non-linear analyses, hydrodynamic pressure obviously increases the principle stress components.

If materially linear and non-linear analyses are compared, lower principle stress components are obtained in the nonlinear analyses.

The stress comparison in the joint between the Blocks I and II

In the comparison of the principle stresses of the Blocks I and II according to linear analyses, the maximum principle tensile and compressive stresses are greater in Block 1.

According to materially non-linear analyses, while the principle stresses are close to each other in empty reservoir case, the principle compressive stresses increase in the bottom of the Block II dam in full reservoir case and decrease in empty reservoir case. Besides, the principle tensile stresses increased in the bottom of the Block II.

\section{The stress comparison in the joint between the Blocks II and III}

The principle stress components are lower in the Block II as compared to Blocks II and III according to materially linear analyses.

The materially non-linear analyses suggest that while the principle tensile stresses are close to each other in both blocks, the maximum stress increases in Block III. Besides, while the principle compressive stresses decreases in full reservoir case, those increase in empty reservoir case in the Block III.

\section{Maximum principle stresses during earthquake}

The maximum principle tensile and compressive stresses are presented during earthquake for empty and full reservoir cases (Fig. 26). The maximum principle stress components are compared according to materially linear and non-linear analyses. The principle tensile and compressive stresses during earthquake resemble their maximum values. While the principle compressive stresses are generally higher in empty reservoir case during earthquake according to linear 


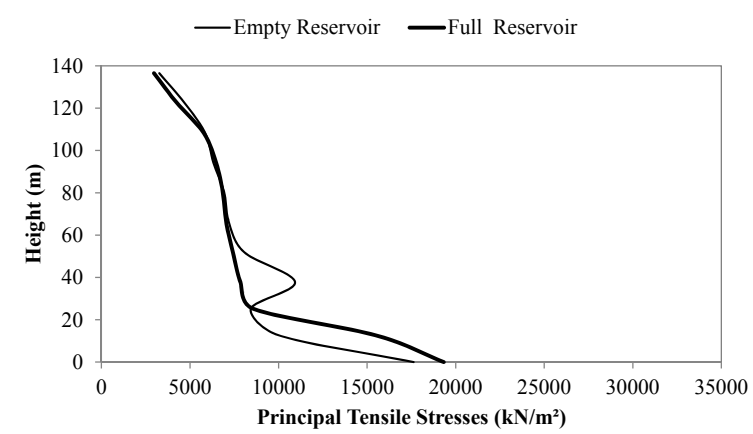

a) The maximum principle tensile stresses according to linear analysis.

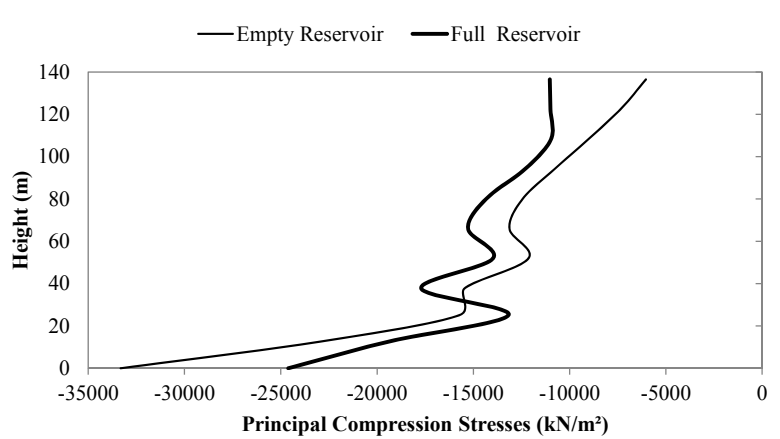

b) The maximum principle compressive stresses according to linear analysis.

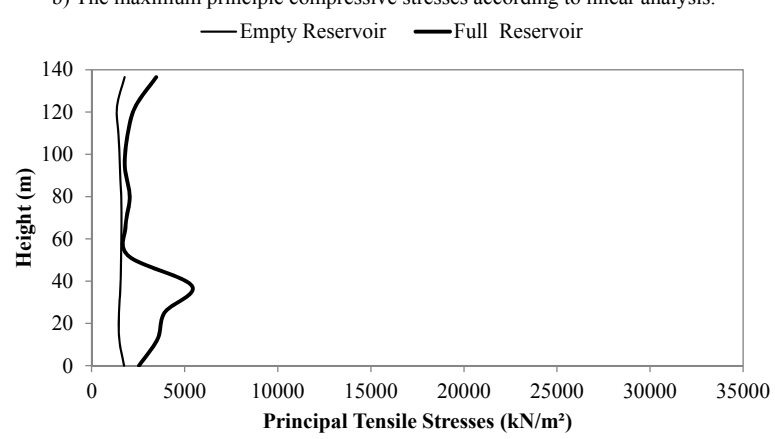

c) The maximum principle tensile stresses according to non-linear analysis.

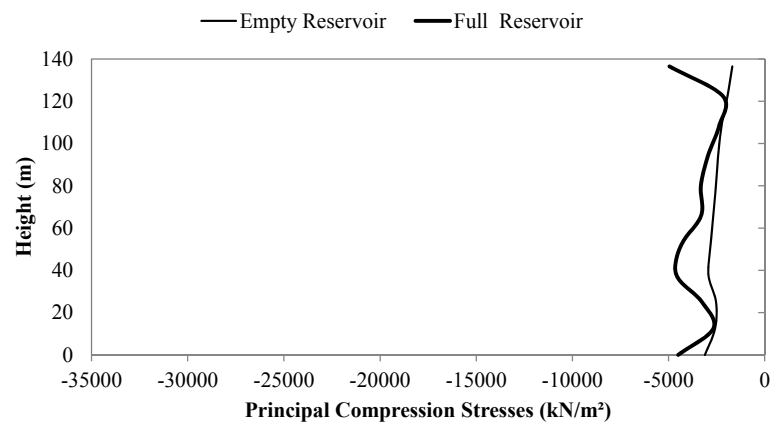

d) The maximum principle compressive stresses according to non-linear analysis.

Fig. 25. The maximum principle stress components in VII-VII section.

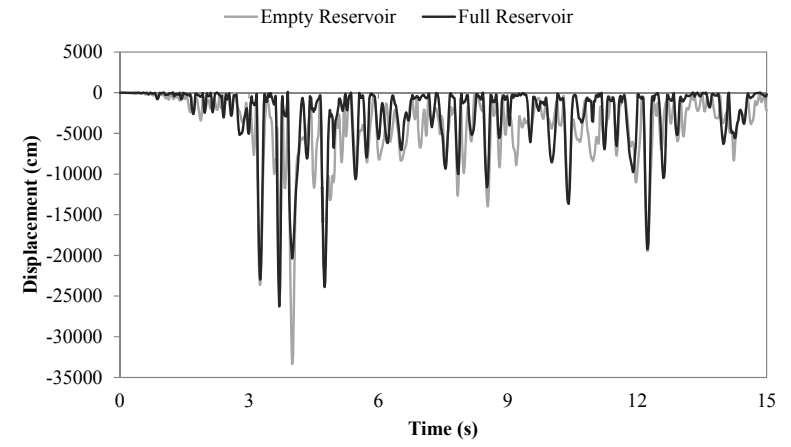

a) The maximum principle compressive stresses according to linear analyses.

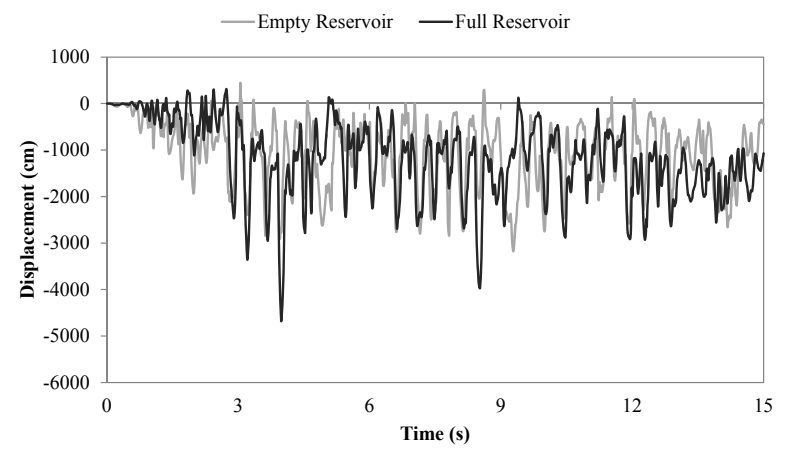

b) The maximum principle compressive stresses according to non-linear analyses.

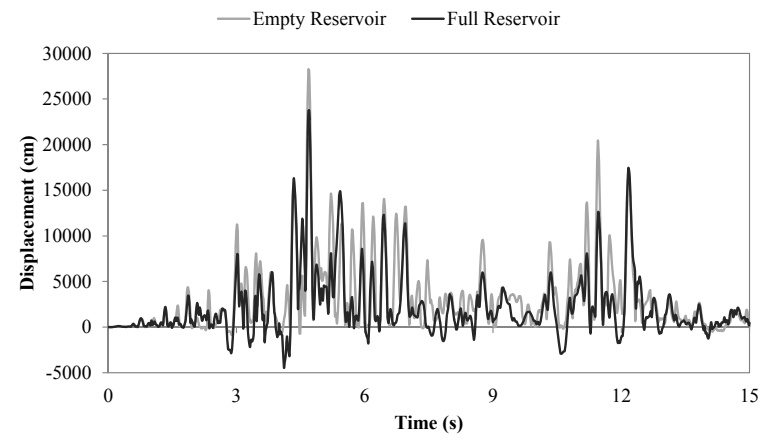

c) The maximum principle tensile stresses according to linear analyses.

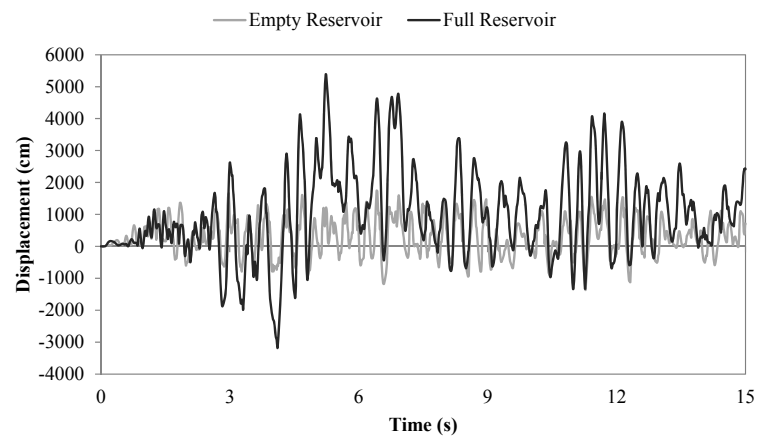

d) The maximum principle tensile stresses according to non-linear analyses.

Fig. 26. The maximum principle compressive and tensile stresses during earthquake. 
analyses, those are generally greater in full reservoir case according to non-linear analyses. Besides, while the principle tensile stresses are generally higher in empty reservoir case during earthquake according to linear analyses, those are clearly and greatly higher in full reservoir case.

\section{Conclusions}

This study presents materially linear and non-linear response of a RCC dam under strong ground motion. Thereby, threedimensional accelerograms of the 1999 Düzce earthquake are employed in the time-history analyses. Geometrical nonlinearity is also considered in the numerical solutions. Bilinear kinematic hardening model is used for dam concrete, and multilinear kinematic hardening model is employed for foundation rock in the materially non-linear analyses. Contraction joints in the RCC dam are modeled by contact elements considering friction contact. Thus, dam-foundationreservoir interaction is modeled using contact-target element pair. Earthquake effects are considered after the gravity and hydrostatic pressure. The hydrostatic and hydrodynamic pressure of the reservoir water is modeled by the fluid finite elements based on the Lagrangian approach. Viscous dampers are utilized in all numerical analyses to represent infinite boundary condition.

According to performed numerical solutions, the followings can be deducted from this study:

- the safer principle stresses are obtained in the materially non-linear analyses compared to linear analyses;

- although no separation contact condition is defined between dam and front soil in full reservoir case, the hydrodynamic pressure of the reservoir still increases the displacements and principle stress components;

- linear analyses clearly suggest that the relative horizontal displacements and the principle stresses decrease in the middle block (Block II) compared to side blocks.

Besides, the following can be proposed in the light of this study:

- the gravity effect and the hydrostatic pressure should be considered as an initial condition before ground motion effects;

- the hydrostatic and hydrodynamic pressure of the reservoir should be considered to obtain critical internal stresses;

- three-dimensional earthquake effects are also considered together with thermal effects to obtain the most critical conditions;

- material, geometrical and connection non-linearity should be employed in the numerical analyses to achieve more reliable results.
Acknowledgements. The author would like express heartfelt thanks to General Directorate of State Hydraulic Works, 21. Regional Directorate, in Aydın and 22. Regional Directorate, in Trabzon for their contributions to this study.

Edited by: M. E. Contadakis

Reviewed by: two anonymous referees

\section{References}

Abdulrazeg, J., Noorzaei, A. A., Bayagoob, K. H., Jaafar, M. S., and Mohammed, T. A.: Three dimensional modeling of thermal and structural analysis of roller compacted concrete dam, 9th International Congress on Advances in Civil Engineering, 2730 September, Karadeniz Technical University, Trabzon, Turkey, 2010.

Akkas, N., Akay, H. U., and Yılmaz, C.: Applicability of generalpurpose finite element programs in solid-fluid interaction problems, Comput. Struct., 10, 773-783, 1979.

Alart, P. and Curnier, A.: A mixed formulation for frictional contact problems prone to Newton like solution methods, Comput. Methods Appl. Mech. Eng., 92, 353-375, 1991.

Ansys: Swanson Analysis Systems Inc., Houston, PA, USA, 2012.

Bathe, K. J.: Finite Element Procedures in Engineering Analysis, Prentice-Hall, Englewood Cliffs, New Jersey, 1996.

Bayraktar, A., Sevim, B., Altunışık A. C., Türker, T., Kartal, M. E., Akköse, M., and Bilici, Y.: Comparison of near and far fault ground motion effects on the seismic performance evaluation of dam-reservoir-foundation systems, Int. Water Power Dam Construct. (Dam Engineering), 19, 1-39, 2009.

Calayır, Y.: Dynamic analysis of concrete gravity dams using the Eulerian and the Lagrangian approaches, Dissertation, Karadeniz Technical University, 1994 (in Turkish).

Chen, Y., Wang, C., Li, S., Wang, R., and He, J.: Simulation analysis of thermal stress of RCC dams using 3-D finite element relocating mesh method, Adv. Eng. Softw., 32, 677-682, 2001.

Chopra, A. K.: Dynamics of Structures: Theory and Applications of Earthquake Engineering, 2nd Edn., Prentice Hall, 844 pp., 1996.

Clough, R. W. and Penzien, J.: Dynamics of structures, 2nd Edn., McGraw-Hill, Singapore, 1993.

DSI: General Directorate of State Hydraulic Works, The XXI, Regional Directorate, Aydın, 2012.

Huang, Y. S.: Analysis on seismic safety of RCC gravity dam with cutting transverse joints, 7th International Symposium on Safety Science and Technology (ISSST), Hangzhou, China, 26-29 October, Part A, 8, 1784-1790, 2010.

Jaafar, M. S., Bayagoob, K. H., Noorzaei, J., and Thanoon, W. A. M.: Development of finite element computer code for thermal analysis of roller compacted concrete dams, Adv. Eng. Softw., 38, 886-895, 2007.

Kikuchi, N. and Oden, J. T.: Contact problems in elasticity: a study of variational inequalities and finite element methods, Philadelphia, SIAM, 495 pp., 1988.

Laursen, T. A. and Simo, J. C.: Algorithmic symmetrization of Coulomb frictional problems using augmented Lagrangians, Comput. Methods Appl. Mech. Eng., 108, 133-146, 1993.

Liapichev, Y. P.: Seismic stability and stress-strain state of a new type of FSH-RCC dams, 4th International Symposium on Roller 
Compacted Concrete Dams, Madrid, Spain, 17-19 November, 2003.

Lysmer, J. and Kuhlemeyer, R. L.: Finite Dynamic Model for Infinite Media, J. Eng. Mech. Division, 95, 859-877, 1969.

Noorzaei, J., Bayagoob, K. H., Thanoon, W. A., and Jaafar, M. S.: Thermal and stress analysis of Kinta RCC dam, Eng. Struct., 28, 1795-1802, 2006.

PEER: Pacific Earthquake Engineering Research Centre, available at: http://peer.berkeley.edu/peer_ground_motion_database (last access: 21 March 2012), 2012.

Rayleigh, J. W. S. and Lindsay, R. B.: The Theory of Sound, Dover Publications, New York, 504 pp., 1945.

Schnabel, P. B., Lysmer, J., and Seed, H. B.: SHAKE: A computer program for earthquake response analysis of horizontally layered sites. Report no. EERC-72/12, Earthquake Engineering Research Centre, University of California, Berkeley, 1972.

USACE: US Army Corps of Engineers. Gravity Dam Design - Engineering and design (engineer manual), EM 1110-2-2200, 1995.
Wilson, E. L. and Khalvati, M.: Finite elements for the dynamic analysis of fluid-solid systems, Int. J. Num. Meth. Eng., 19, 1657-1668. 1983.

Wriggers, P.: Computational contact mechanics, 2nd Edn., Netherlands, Springer Verlag, 2006.

Wriggers, P., Simo, J., and Taylor, R.: Penalty and augmented Lagrangian formulations for contact problems, in: Proceedings of the NUMETA conference, edited by: Middleton, J. and Pande, G., Rotterdam, Balkema, 1985.

Zhang, G. X., Liu, G. T., and Wu, Y.: Harmonic thermal fracture of multiple crack system and the stability of cracks in RCC arch dam, Eng. Fract. Mech., 54, 653-665, 1996.

Zhang, X., Li, S., Li, Y., Ge, Y., and Li, H.: Effect of superficial insulation on roller-compacted concrete dams in cold regions, Adv. Eng. Softw., 42, 939-943, 2011.

Zienkiewicz, O. C. and Taylor R. L.: The Finite Element Method, Mc Graw-Hill, 1989. 